Forthcoming in Journal of Financial Economics

\title{
IPO Allocations: Discriminatory or Discretionary? ${ }^{* \dagger}$
}

\author{
Alexander P. Ljungqvist \\ Stern School of Business \\ New York University \\ and $C E P R$
}

\author{
William J. Wilhelm, Jr. \\ Saïd Business School \\ Oxford University
}

First draft: January 20, 2001

This draft: August 29, 2001

\footnotetext{
${ }^{*}$ We are especially grateful to the referee for detailed comments that substantially improved the paper. We also thank William Greene, Michel Habib, Maureen O'Hara, Jay Ritter, G. William Schwert (the Editor), and participants at the NYSE "Global Equity Markets in Transition" conference (Hawaii, 2001), the Third Toulouse Finance Workshop, and seminars at Oxford University, the University of Wisconsin-Madison, the University of North Carolina at Chapel Hill, and the University of Virginia for helpful comments. We wish to thank the many companies, banks, and bourses which made data available. All errors are our own.

${ }^{\dagger}$ Address for correspondence: Stern School of Business, New York University, Suite 9-190, 44 West Fourth Street, New York NY 10012-1126. Phone 212-998-0304. Fax 212-995-4233. e-mail aljungqv@ stern.nyu.edu.
} 


\title{
IPO Allocations: Discriminatory or Discretionary?
}

\begin{abstract}
We estimate the structural links between IPO allocations, pre-market information production, and initial underpricing and find that

- allocation policies favor institutional investors, both in the U.S. and worldwide

- increasing institutional allocations results in offer prices that deviate more from the premarketing price range

- constraints on bankers' discretion reduce institutional allocations and result in smaller price revisions, indicating diminished information production

- initial returns are directly related to information production and inversely related to institutional allocations

Our results indicate that discretionary allocations promote price discovery in the IPO market and reduce indirect issuance costs for IPO firms.
\end{abstract}

Key words: Initial public offerings; Bookbuilding; Underpricing; Intermediation. JEL classification: G32, G24 


\section{Introduction}

IPO allocation policies favor institutional investors. This is well known, although rather less well documented, in the U.S. In this paper, we show that the same is true worldwide. Averaging across 37 countries and 1,032 IPOs between 1990 and 2000, we find that share allocations to institutional investors are virtually double those received by retail investors. The available evidence from the U.S. indicates much the same (Hanley and Wilhelm, 1995; Aggarwal, 2000).

How should this empirical fact be interpreted? In the U.S., allocation policies are discretionary - there are few rules to guide or constrain investment bankers. Outside the U.S., allocation discretion is frequently constrained and yet the end result, in allocations at least, appears much the same. Benveniste and Wilhelm (1990) suggest that banker discretion can benefit issuers facing asymmetrically informed investors because such investors may be induced to reveal their information in return for favorable allocations. On the other hand, it is not hard to imagine bankers exercising discretion to favor institutional investors with whom they maintain long-term relationships. The open question is whether, on net, "discretionary" share allocation is beneficial or whether it should more accurately and pejoratively be thought of as a "discriminatory" practice that serves the bankers' interests at the expense of other parties to the transaction.

This question gained force on December 7, 2000 when the Wall Street Journal alleged that in exchange for IPO allocations, bankers require institutional investors to purchase shares in the secondary market or pay unusually high trading commissions. ${ }^{1}$ The Securities and Exchange Commission and the U.S. attorney's office in Manhattan responded by announcing investigations to determine whether these allegedly common demands violate regulations barring tie-ins. It is worth noting that discretionary use of either tactic provides for extracting a unique all-in 'price'

\footnotetext{
${ }^{1}$ See Smith and Pulliam (“U.S. Probes Inflated Commissions for Hot IPOs”, Wall Street Journal, Dec. 7, 2000, p. C1) as well as subsequent articles. Also see the seven-part series beginning May 2, 2001 in Red Herring.
} 
from each investor receiving an initial allocation and therefore could be interpreted as a means of (implicit) price discrimination. Explicit price discrimination in the sale of IPOs is prohibited in the U.S. as well as in most other jurisdictions.

In this paper we attempt to shed light on the rather complex question of whether such discriminatory practices undermine primary market efficiency. The complexity begins with identifying an appropriate objective for pricing and allocation policies. The bulk of academic theory treats maximization of proceeds received by the issuer as the appropriate objective. Although there is merit in this assumption in the context of well-developed capital markets, it is less obviously appropriate for privatization IPOs or when it is hoped that broad share ownership will spur the development of secondary markets or serve some other public interest. Some might even argue for non-discriminatory allocations on egalitarian grounds regardless of the consequences for issuing firms.

For the purpose at hand, we implicitly take proceeds maximization, net of issue costs, as the appropriate objective of a pricing and allocation policy. We believe this approach sheds more light on the ongoing debate in the U.S. and is increasingly germane to policymakers worldwide. But it also requires careful consideration of the source and magnitude of the indirect costs of issuance. Initial public offerings are typically discounted or "underpriced", in the sense of large first-day price increases, and institutional investors are the primary beneficiaries.

Benveniste and Spindt (1989) argue that this substantial indirect cost of bookbuilding reflects a quid pro quo arrangement with institutional investors whose non-binding bids or "indications of interest" provide the foundation for establishing the issuer's offer price. Absent "compensation" (in the form of large allocations of underpriced shares), institutions would have little incentive to bid aggressively knowing that to do so would only drive up the offer price. But indiscriminate 
allocation of underpriced shares rewards both informed (aggressive) and uninformed bidders. Although discriminatory allocation of underpriced shares diminishes the issuer's proceeds from the offering ex post, in this view, expected proceeds are maximized (Benveniste and Wilhelm, 1990; Sherman and Titman, 2000). The empirical predictions from this theory are that allocation constraints diminish information production and the issuer's expected net proceeds (as underpricing is substituted for larger institutional allocations in the "compensation package" provided to institutional investors). ${ }^{2}$

Alternatively, allocation discretion might aggravate an agency problem between the issuer and its banker (Baron, 1982) arising from the fact that bankers deal repeatedly with institutional investors but infrequently with issuers. Biais, Bossaerts, and Rochet (1999) examine this possibility by assuming that bankers and institutional investors collude to extract informational rents from issuers. Once again, the optimal price and allocation mechanism (from the issuer's perspective) favors informed investors with discounted share allocations. ${ }^{3}$ However, in broad terms, agency problems related to allocation discretion can be hypothesized to undermine the issuer's interests. Thus we might expect allocation constraints to diminish underpricing and lead to a complementary relation between initial returns and institutional allocations (as bankers curry favor among institutional investors by providing larger allocations in discounted offerings).

\footnotetext{
${ }^{2}$ Benveniste, Busaba, and Wilhelm (1996) extend the analysis by showing that discretionary implementation of "penalty bids" designed to prevent immediate sale of initial share allocations by some investors can increase expected proceeds by providing another instrument for price discrimination. Bankers routinely attempt to prevent secondary market prices from declining below the offering price. In this context, penalty bids buoy secondary market prices by counterbalancing selling pressure. In other words, they are economically equivalent to the alleged demands from bankers that investors purchase shares in the secondary market in exchange for initial share allocations. But allowing some investors to sell at the offer price while preventing others from doing so, is also equivalent to providing some initial investors with put options in addition to their share allocations but withholding them from others. Thus for the same (offer) price, some investors receive shares and put options while others receive only shares.

${ }^{3}$ However, price discrimination is not optimal in this setting whereas both price and allocation discrimination can be optimal in the Benveniste and Wilhelm (1990) setting. In a similar vein, Biais and Faugeron-Crouzet (2000) identify a parallel between France's Mise en vente auctions and bookbuilding by establishing conditions under which both implement the optimal price and allocation mechanism.
} 
Although the limited documentation of allocation policy in the literature appears consistent with the Benveniste and Spindt (1989) interpretation, it is premature to accept discretion as a good thing on the basis of these studies alone. Most empirical studies have focused on relatively narrow, reduced-form tests of the theory, often ignoring serious endogeneity problems, rather than testing the broader structure implied by the mechanism design perspective. ${ }^{4}$ In this paper, we estimate a structural model designed to put the mechanism design theory to a more severe test. One noteworthy finding is that the bookbuilding theory survives our test.

Most existing tests of the bookbuilding theory have also been limited to the U.S. (Cornelli and Goldreich, 1999, 2000 are the noteworthy exceptions). The problem with U.S. data, apart from the general unwillingness of U.S. banks to share information about their allocation policies, is that it provides no useful alternative for comparison. Banks maintain full allocation discretion in all U.S. firm-commitment IPOs. Outside the U.S., bookbuilding practices have virtually supplanted the traditional fixed-price offering, and its pro rata allocation policy, in much of Continental Europe and increasingly in Asia (Ljungqvist, Jenkinson, and Wilhelm, 2001). But these countries have also imposed a wide range of regulatory constraints on allocation policies. At one extreme, the German primary markets are increasingly dominated by bookbuilding practices and, like the U.S., impose few constraints on how shares are allocated. At the other extreme are countries like Australia where fixed price offerings with pro rata allocations are the default option given to issuing firms. In the middle lie countries like France and the United Kingdom where issuers can

\footnotetext{
${ }^{4}$ See, for example, Hanley (1993). Hanley and Wilhelm (1995) and Cornelli and Goldreich (1999, 2000). These studies are constrained from estimating a structural model by the fact that they have allocation data only for a single bank. The structural test performed by Biais et al. (1999) suffers from limited data and, for our purposes, the fact that allocation policy in the Mise en vente, while discriminatory, provides bankers with limited discretion. By contrast, Ljungqvist, Jenkinson, and Wilhelm (2001), using data similar to ours, account for the econometric consequences of issuers selecting from a 'menu' of price and allocations mechanisms when they go public.
} 
select from a range of underwriting practices and banks are subject to a variety of constraints on the discretion they exercise in the allocation of shares.

This heterogeneity in allocation policy creates variation that increases the power of our structural econometric model. In turn, estimation sheds light on whether discretionary allocation is beneficial on net, and if so, under what circumstances. The following results should be of interest to policy makers:

- Constraints on bankers' allocation discretion reduce institutional allocations.

- Constraints on allocation discretion result in offer prices that deviate less from the indicative price range established prior to bankers' efforts to gauge demand among institutional investors. We interpret this as indicative of diminished information production.

- Initial returns are directly related to this measure of information production and inversely related to the fraction of shares allocated to institutional investors.

We tentatively conclude that discretionary allocation does not pose a net cost to issuers because it promotes price discovery in primary markets and diminishes the attendant costs of information acquisition.

\section{Sample and Data}

Our dataset spans the period January 1990 to May 2000 and covers a large fraction of the IPOs brought to market worldwide during the decade. The 1990s are noteworthy both for the high level of primary market activity and also as a period of unprecedented experimentation in the means by which issuing firms were marketed to investors. The sharp increase in global offerings required banks to develop mechanisms to appeal to a wide range of investor preferences and abide by a similarly wide range of regulatory constraints. By the end of the decade, a large fraction of IPOs 
were carried out by methods that involved discretionary share allocation for at least part of the offering (Ljungqvist et al., 2001).

\subsection{Sample construction}

We assemble a large dataset of IPOs from a variety of sources, detailed below. While we do not have allocation data for every IPO in this dataset, we still require as comprehensive a dataset as possible, in order to derive certain measures of aggregate IPO activity for our econometric model. The econometric model, in turn, focuses on firms floating in four countries - France, Germany, the U.K., and the U.S. - which are subject to a wide range of constraints described later.

Throughout the paper, observations per country refer to the number of firms going public in that country, including foreign issuers. We adopt this convention because rules on allocation discretion are formulated at the level of the country of listing, not the country of origin. Where a company lists in more than one country, we define its main listing as being in its home country, or if it only lists abroad as the country where the bulk of the offering is conducted.

Specifically, the dataset consists of three parts, covering the 15 countries of the European Union (EU15), non-EU Europe, and Rest of the World. Throughout, we exclude IPOs by investment trusts, companies previously listed elsewhere, and introductions (listings not accompanied by the sale of securities, common in the U.K.). The EU15 part consists of 2,967 IPOs and captures offerings anywhere in the world by firms based in an EU15 country as well as offerings in an EU15 country by firms based anywhere in the world:

\begin{tabular}{ccr}
\hline Issuers based in the 15 & Issuers listing in the 15 & Number of \\
European Union countries & European Union countries & IPOs \\
\hline$\sqrt{ }$ & $\sqrt{ }$ & 2,861 \\
$\sqrt{ }$ & $x$ & 82 \\
$X$ & $\sqrt{ }$ & 24 \\
\cline { 2 - 3 }
\end{tabular}


These 2,967 offerings were identified from five principal sources:

- the Equityware database (between January 1992 and July 1999) (see Ljungqvist et al., 2001, for further details);

- the SDC Global New Issues database, from which we extract all IPOs not already covered in Equityware (619 cases, of which 324 were conducted before January 1992 or after July 1999);

- information provided by European stock exchanges;

- a search of every article in Reuters' "Share issues" news archive for each EU15 country;

- and Ljungqvist's (1997) database of German IPOs.

Every offering contained in these sources was checked for eligibility as a bona fide IPO against IPO prospectuses and regulatory filings because we found that SDC frequently misclassifies seasoned offerings as IPOs and double-counts IPOs under different names. ${ }^{5}$

The EU15 sample is relatively comprehensive. In addition, we have access to a less comprehensive sample of 98 IPOs by issuers in non-EU Europe and 695 IPOs by issuers in the rest of the world (excluding the U.S.), over the period January 1992 to July 1999. These offerings were identified using Equityware.

\subsection{Allocation data}

The transparency of the distribution of shares between retail and institutional investors varies substantially across countries. Some countries follow the U.S. in not requiring this information to be made public. Until recently, this was the case in Germany, so to gather allocation data we

\footnotetext{
${ }^{5}$ We are grateful to Wolfgang Aussenegg, Jan Jakobsen, François Derrien, and Giancarlo Giudici for looking over our Austrian, Danish, French, and Italian samples, respectively.
} 
approached companies directly. There were 470 IPOs in Germany during our sample period. Of these, 377 were bookbuilding exercises, 92 were fixed-price offerings, and one was conducted by auction. See Appendix A for details of offering mechanisms and allocation rules in Germany.

Bookbuilding became the dominant offering mechanism in 1995, accounting for $94 \%$ of German IPOs in 1995-2000. Our survey was conducted in May and June 2000 and targeted all 351 firms which went public in Germany between January 1996 and March 2000 (we also contacted a sample of pre-1996 issuers in a trial but found that none would provide allocation data). Responses were received from 106 firms (30\%). Of these, 93 disclosed their allocations, five said they no longer had the data, five were unwilling to make the data available, and three sent data pertaining to subsequent seasoned equity offerings. In addition, we received detailed allocation data for 36 IPOs from an underwriter (widely regarded as the market leader in IPOs on the Neuer Markt, Germany's dominant primary market). Finally, we obtained allocation data for 15 additional firms from press releases. This provides a sample of 144 IPOs in Germany for which allocation data are available, covering $38 \%$ of all IPOs since 1996. Three of these IPOs cannot be used in the econometric analysis for lack of indicative price ranges (two were fixed-price offerings and one was sold by auction).

By contrast, in France the Bourse generally requires issuers to report allocations, though public availability of the notifications is patchy in the case of flotations on the over-the-counter markets. During the sample period there were 516 IPOs in France. 28 went public on the Premier Marché, 247 on the Second Marché, 124 on the Nouveau Marché, and 117 on an OTC market (the Paris Marché Libre, its predecessor, the Marché Hors-Cote, or the OTC markets in Lyon and Nantes). Of these, 255 were pure or hybrid bookbuilding exercises, 44 were fixed-price offers, and 185 were conducted via auctions; 32 OTC offerings could not be classified (though they are likely to 
be auctions). See Appendix B for details of offering mechanisms and allocation rules in France. Allocation data for auctions are not publicly available. Among non-auctions, we obtain allocation data from the Bourse for 237 of the 255 bookbuilding efforts, and 7 of the 44 fixed-price offers. In total, we thus have allocation data for 244 issues. This covers virtually the entire population of bookbuilt IPOs, and about half of all French IPOs during the sample period. Seven of the bookbuilt IPOs are excluded from the econometric analysis for lack of indicative price ranges.

In the U.K., there were 876 IPOs on the London Stock Exchange between January 1990 and May 2000. 515 went public on the Official List, 19 on the Unlisted Securities Market (USM, from 1990 to 1995), and 342 on the Alternative Investment Market (AIM, from June 1995 to May 2000). We exclude companies transferring from one London market tier to another (including from the Rule 535.2 or 4.2 trading facility which replaced the Third Market), companies traded on Ofex (an unregulated trading facility operated by J.P. Jenkins, a firm of stockbrokers), and introductions (listings not accompanied by the sale of securities).

As discussed in Appendix C, U.K. offerings can be categorized as 'placings' (651 cases), 'public offers' (12 cases), 'hybrids' (which combine a placing with a public offer; 178 cases), or 'global offers' (which combine a listing in London with one abroad, usually in the U.S.; 35 cases). Allocation policies for the first two are virtually binary. Placings are not registered for offering to the public at large and so involve only institutional investors or extremely wealthy individuals. In some instances, placings set aside a proportion of shares for employees. On the other hand, public offers, which are allocated on a pro-rata basis or by ballot, are nearly exclusively a retail phenomenon. We were able to obtain allocation data for 186 of the 213 hybrid or global offers from the London Stock Exchange, which like the Paris Bourse requires publication of the 'basis 
for allocation'. In addition, we know the allocations for all placings and most public offers, giving a total of 843 IPOs for which allocation data are available.

To provide a link to the published literature on IPO allocations, which uses U.S. data, we include a sample of IPOs in the United States. U.S. banks and issuers are not required to reveal how shares were allocated across various investor clienteles. However, we have access to a small sample of 30 U.S. firms taken public in the U.S. by Goldman Sachs between March 1993 and July 1995, as well as two European firms which went public in the U.S. This sample does not overlap with those previously used by Hanley and Wilhelm (1995) and Aggarwal (2000).

For all four countries, our allocation data reflect the aggregate allocations of the entire syndicate, rather than - as in Hanley and Wilhelm (1995) and Aggarwal (2000) - of the lead manager only. Our data thus allow us to more precisely measure allocation policy than is the case in the extant literature.

Our econometric model focuses on the IPOs in the four countries just described. In addition, we have allocation data for 426 IPOs in other countries which we include for descriptive purposes. For some countries (for instance Finland), the data come from filings with the local stock exchange. For the remainder, we rely on information about the final tranche structure in hybrid deals to infer retail and institutional allocations. ${ }^{6}$

\footnotetext{
${ }^{6}$ Suppose the issuer announces tranches of 1 million shares for retail investors and 2 million shares for institutions. This information is typically contained in the preliminary offering prospectus. Depending on local rules, the issuer may or may not reallocate between tranches in the light of relative demands. On the assumption that institutions do not submit bids pretending they are retail investors, and vice versa, we use the final tranche sizes to compute the institutional/retail split (taking into account the overallotment option, which frequently benefits institutions). Information regarding final tranche sizes is obtained from issuer reports to their stock exchange or press announcements by the underwriter or the issuer. Given this procedure, we are unable to infer allocations in non-hybrid offerings in cases where no voluntary or mandatory disclosure takes place.
} 


\section{A Global Perspective on IPO Allocations}

Table 1 reports summary statistics for institutional allocations in our sample, broken down by country of listing. With few exceptions among the countries for which we have more than a few observations, institutional allocations outnumber retail allocations by something in the neighborhood of 2 or 3 to 1 , on average, when banks have discretion in how shares are allocated. For example, institutions receive $76 \%$ of IPO shares in France and $73 \%$ in those U.K. IPOs which are open to both institutional and retail investors. In the small sample of Goldman-backed U.S. IPOs, institutions take $66 \%$ of the average offer. On the other hand, German IPOs yield slightly lower discretionary allocations to institutions of about $58 \%$ on average. Across the 1,689 IPOs for which we have allocation data, the average institutional allocation is $80 \%$, though this reflects the large number of U.K. placings. Excluding these, the average drops to $69 \%$.

In the remainder of the paper, we focus on IPOs in France, Germany, the U.K., and the U.S. Because we do not have allocation data for every IPO in these countries, we are concerned about the potential for sample selection bias. As a first cut, Table 2 provides, for each of the four countries, summary statistics regarding offer size, underpricing, allocations to institutions, and the number of privatizations. For each country, we test for differences in means or medians between the full country sample (column [1]) and the sample for which we have allocation data (column [2]). This reveals no significant differences in Germany or the U.K. In France, median gross proceeds is significantly higher amongst firms for which we have allocation data, reflecting the fact that smaller issuers are more likely to use an auction to price their securities. To see how representative our small U.S. sample is, we compare it to an SDC-generated sample of 2,353 common-stock IPOs in the U.S. between January 1990 and May 2000 which were lead-managed by 'top-tier' banks (ranked 8.75 or higher on Carter and Manaster's 9-point scale). The U.S. 
offerings for which we have allocation data are significantly larger than the average or median U.S. IPO lead-managed by a top bank, and are a little less underpriced.

Availability of allocation data is only a necessary condition for inclusion in our econometric model. In addition, we require data on the initial price range in order to measure the degree of price discovery in the pre-market. This requirement reduces the number of available IPOs from 843 to 231 in the U.K. (where indicative price ranges have not traditionally been disclosed publicly), with negligible losses in France (from 244 to 237) and Germany (from 144 to 141). Table 2 also provides tests for differences between the sample for which we have allocation data (column [2]) and the reduced sample for which we have both allocation and price range information (column [3]). There are some significant differences among U.K. offerings, which treble in terms of average and median offer size. This is largely due to the fact that we lack indicative price ranges for many placings. Before 1996, placings were confined to smaller issues (up to $£ 15$ million till December 1993, up to $£ 25$ million till December 1995), while larger issuers were compelled to use a hybrid. Due to the attrition amongst placings, average institutional allocations fall from $93 \%$ in column [2] to $86.3 \%$ in column [3]. We are also more likely to have allocation and price range data for privatizations, not surprisingly given their larger size.

Across the four countries, the average company raises $\$ 75$ million, the median $\$ 28$ million, and underpricing averages $26 \%$. Amongst the 641 firms for which we have both allocation and price range information, the average company raises $\$ 215$ million, the median $\$ 31$ million, and underpricing averages $22 \%$. Given these patterns, we need to take sample selectivity bias seriously. We will outline a Heckman (1979) selectivity correction in Section 6. 


\section{The Determinants and Consequences of Allocation Policy}

The empirical framework used to analyze the 641 IPOs in France, Germany, the U.K., and the U.S. described in Table 2 derives from Benveniste and Spindt (1989). Benveniste and Spindt view discretionary allocation as a key element of the investment bank's effort to extract private information from potential investors prior to setting the offer price for an IPO. Allocation policy, in turn, is influenced by these strategic considerations and various constraints imposed by the regulatory regime under which the IPO is conducted. In the remainder of this Section we outline the theory underpinning these elements of the econometric model and conclude with a discussion of the identification and estimation of the implied system of equations describing the market. The precise definitions of all our variables can be found in Table 3.

\subsection{Price discovery in primary markets}

By price discovery in primary markets we mean the degree to which prior expectations regarding the value of the offering, reflected in preliminary filings with the issuer's regulator, are revised in response to feedback from investors and the market at large before the offer price is set. Thus we think of the offer price as reflecting a conditional expectation representing the culmination of primary market price discovery. The literature has proposed two main proxies for the learning reflected in the difference between these conditional and unconditional expectations. Cornelli and Goldreich (2000) define the variable Revision $=\left(\right.$ Offer Price $\left.-P_{\text {low }}\right) /\left(P_{\text {high }}-P_{\text {low }}\right)$, where $P_{\text {high }}$ and $P_{\text {low }}$ are the upper and lower bounds of the indicative price range generally filed with the issuer's regulator prior to seeking feedback from institutional investors in the course of bookbuilding. Hanley (1993) measures learning instead as Offer Price $/\left[1 / 2\left(P_{\text {high }}+P_{\text {low }}\right)\right]-1$. To ensure our results are easily comparable to the related clinical analysis in Cornelli and Goldreich 
(2000), we follow their approach. The only consequence of this scaling decision is a slight increase in standard errors over those obtained using Hanley's approach.

By construction, Revision $=1 / 2$ if the offer price is set at the midpoint of the price range, indicating that no new information has emerged. Revision is negative if the offer is priced below the range, 0 if priced at $P_{l o w}, 1$ if priced at $P_{\text {high }}$, and greater than 1 if priced above the range. In our data, Revision averages 0.68 in France, 0.84 in Germany, 0.49 in the U.K., and 0.74 in the U.S.

Benveniste, Busaba, and Wilhelm (2001) argue that issuers learn not only through their own marketing efforts but also through those of their rivals. In other words, price discovery is a function of both deal-specific information and information spilling over from contemporaneous transactions and perhaps secondary market activity. (For empirical evidence consistent with this prediction, see Lowry and Schwert, 2000; Benveniste, Ljungqvist, Wilhelm, and Yu, 2001.) Spillover effects from contemporaneous transactions are controlled by the mean, $m_{-}$Revision $_{B B}$, and standard deviation, $\sigma_{-}$Revision $_{B B}$, of price revisions for contemporaneous IPOs in the same local market. The volatility measure, $\sigma \_$Revision $_{B B}$, is included to control for noise and idiosyncratic information reflected in contemporaneous revisions. In other words, if contemporaneous IPOs are subject to a common information factor, we assume that the influence of this common information on price revisions is comparable in magnitude across IPOs. Deviations from the mean reflect noise or idiosyncratic factors that reduce the precision of learning about the common factor.

IPO $i$ 's contemporaries are defined as all local IPOs that were priced between the dates for setting $i$ 's indicative price range and finalizing its offer price. If there are no contemporaneous IPOs, or none that use bookbuilding, $m_{-}$Revision $_{B B}$ and $\sigma \_$Revision $_{B B}$ are set to $1 / 2$ and 0 respectively (our results are robust to using windows of fixed width which have the advantage of 
reducing the occurrence of no contemporaneous IPOs). All measures of contemporaneous activity are estimated using the full country samples described in column [1] of Table 2.

We refer to the period between the setting of the indicative price range and the final offer price as the bookbuilding phase and subscript all variables defined during this period by 'BB' ${ }^{7}$ The bookbuilding phase averages 15 calendar days in France, 11 days in Germany, and 17 days in the U.K. (see Appendix D). If spillovers from contemporaneous offerings are substantial, we expect a positive relation between Revision and $m_{-}$Revision ${ }_{B B}$. However, when the signal-to-noise ratio for information generated by contemporaneous offerings is low, less learning occurs and so Revision should be negatively related to $\sigma \_$Revision $_{B B}$.

In the Benveniste-Spindt framework, discounted share allocations constitute the compensation provided in exchange for investors' private information. Other things equal, large price revisions, reflecting a greater yield of private information, will carry the expectation of a larger discount. This is the well-documented 'partial adjustment' phenomenon observed in both the U.S. (Hanley, 1993; Lowry and Schwert, 2000; Loughran and Ritter, 2001) and worldwide (Ljungqvist et al., 2001). The partial adjustment phenomenon also suggests that if spillovers are important, contemporaneous revisions tell only part of the story. In isolation, a moderate positive contemporaneous revision might be interpreted as revealing only a moderate amount of information. But if it is coupled with a large initial return, the Benveniste-Spindt framework predicts the combination reflects a strong positive response. We control for this effect by including

\footnotetext{
${ }^{7}$ We use the precise dates on which the price range and the offer price were set in each case. Note that these generally precede the announcement date by a day or two. Since we are here interested in the information set of the issuer and not of outside investors, we collect the earlier dates. We obtained these as follows: in France, from the market regulator (the Commission des Opérations de Bourse) and the Paris Bourse; in Germany, from the final IPO prospectus (which recapitulates the sequence of events); in the U.K., from the London Stock Exchange's Regulatory News Service and from the 'expected timetable of principal events' in the 'pathfinder' (preliminary) prospectus. In the U.S., we use SEC filing and effective dates from Securities Data Company.
} 
the mean of the one-day initial return of all local IPOs whose first trading day occurs during IPO $i$ 's bookbuilding phase, $m_{-} I R_{B B}$, in addition to the contemporaneous revision variables.

Secondary market spillovers are measured by the return to a local market index during each IPO's bookbuilding phase $\left(\right.$ MktRet $\left._{B B}\right)$ as well as the standard deviation of daily index returns during the same period $\left(\sigma_{-} M k t_{B B}\right)$. The rationale for including $\sigma_{-} M k t_{B B}$ mirrors that for $\sigma_{-}$Revision $_{B B}$. Although large market movements might be reflective of the arrival of considerable new information bearing on an IPO's offer price, when volatility is high it is difficult to tease out its implications. So again, IPO i’s price revision should be directly related to $\operatorname{MktRet}_{B B}$ and negatively related to $\sigma_{-} M k t_{B B}$.

Controlling for these potential spillover effects, Benveniste and Wilhelm (1990) predict that banker discretion promotes price discovery. The banker's level of discretion differs across the four countries and, in the case of France and the U.K., within countries. The various options facing issuers in France, Germany and the U.K. are outlined in Appendices A-C. Since it is impossible to quantify the relative discretion granted to bankers across deals we define two categories of constraints on banker discretion and outline these in Table 4. Classification is based on the operative rules announced in the preliminary prospectus or regulatory filings.

Our first category of constraints includes deals subject to a variety of constraints limiting banker discretion in offerings open to both retail and institutional investors. For example, fixedtranche deals in France and the U.K., where allocations for different classes of investors are fixed in advance of the bookbuilding effort, clearly remove a degree of freedom that might prove valuable in the mechanism-design framework. Similarly, some hybrid transactions, particularly in the U.K., include an automatic clawback provision triggered by retail demand. In essence, such provisions enable retail investors to condition their demand on feedback received from 
institutional investors. When institutional demand is strong, retail investors can follow suit and the clawback provision calls for the banker to reassign shares to retail investors that otherwise would have been assigned to institutional investors. But institutional investors, recognizing that strong indications of interest will only cause them to be crowded out by retail investors, will have weaker incentives to step forward with strong indications in the first place. Finally, the sample includes 7 French fixed-price offerings, which (perhaps surprisingly) post an indicative price range enabling their inclusion in the analysis. These fixed-price offerings provide underwriters with no discretion because shares are simply allocated on a pro rata basis. In total, 18 French and 87 UK offerings fall within our first category of constraints which we designate with the dummy variable BB_constraints.

The estimation sample also includes 126 U.K. placings that can only be sold to institutional investors (ignoring the fact that ten of these set aside between $1 / 2 \%$ and $20 \%$ of the offer for their employees). These offerings are designated with the dummy variable $B B \_p l a c i n g s$. In this setting, retail investors no longer provide the fallback in bargaining with institutional investors envisioned by Benveniste and Wilhelm (1990). For example, suppose the underwriter had reason to believe that investors were deliberately understating their demand in hopes of forcing a lower price. The optimal response in the Benveniste-Spindt framework is to reduce institutional allocations by allocating more to retail investors. However, deliberately misrepresenting positive views is not an optimal response to the underwriter's optimal response, and so this is not a Nash equilibrium unless there are constraints on the underwriter's ability to switch allocations to retail investors. In the presence of constraints, misrepresenting positive views may be a Nash strategy, to the extent that the institutions' profits on their reduced (but nonzero) allocations are greater than the profits from truthful revelation of their information. One plausible constraint is that there aren't enough 
retail investors and so some institutions receive nonzero allocations. In U.K. placings the offering is not registered for sale to retail investors and so we have the worst-case scenario. Although this is a constraint on the banker's capacity for eliciting information from institutional investors neither its absolute magnitude nor its magnitude relative to that of the constraints captured by $B B \_$constraints are clear a priori. ${ }^{8}$

The remaining offerings are classified as unconstrained bookbuilding efforts. In addition to U.S. and German IPOs, this category also includes dual-tranche deals which do not pre-commit the underwriter to particular tranche sizes, as in U.K. 'global offers' which typically state that the final tranche structure is to be decided after the offer closes, or French hybrid bookbuilding efforts which provide for the possibility of clawback (usually but not exclusively in favor of retail investors) but leave the decision whether to exercise the clawback option with the underwriter.

Finally, note that the banker in the Benveniste-Spindt framework simultaneously determines how much to allocate to investors who relinquish private information and how much to revise the offer price in response, so what we observe is the equilibrium combination of price (Revision) and quantity (allocations). We therefore let Revision depend on allocations to institutional investors.

Even after controlling for the level of explicit constraints on discretion, local custom or other circumstances might influence banker expectations regarding their capacity to favor certain investors in exchange for information. We therefore normalize ex post institutional allocations by the average institutional allocation in contemporaneous offerings (local offerings during the three months preceding firm $i$ 's IPO). This variable, which we call Inst_Alloc, will be greater than 1 if

\footnotetext{
${ }^{8}$ If this argument is correct and it is more difficult to induce truthful revelation in placings, the problem should be attenuated if there exist other sources of leverage over the participating institutional investors. For instance, if the underwriter deals repeatedly with the same institutions, it may credibly threaten to cease future dealings with an institution perceived as deliberately misrepresenting its demand. Consistent with this argument, we find that placings are associated with smaller revisions but that the effect is mitigated, the greater the lead manager's market share.
} 
institutions are allocated more than is 'normal' in that market at that time. We assume that for U.K. placings the normal allocation is 1 . Our normalization enables us to pool data from across countries but assumes that allocation practices are comparable across countries after regulatory and other differences are controlled. Later we test this assumption and examine the robustness of our results to alternative specifications. Clearly, Inst_Alloc is endogenous according to the Benveniste-Spindt framework, and our estimation will control for this.

In summary, the model of primary market price discovery to be estimated is:

$$
\begin{gathered}
\text { Revision }=f_{1}\left(\text { Inst_Alloc }, m \_ \text {Revision }_{B B}, \sigma \_ \text {Revision }_{B B}, \text { MktRet }_{B B}, \sigma{ }_{-} \text {Mt }_{B B}\right. \text {, } \\
\left.m \_I R_{B B}, B B \_ \text {constraints }, B B \_ \text {placings }\right)
\end{gathered}
$$

\subsection{Allocation policy}

We assume that institutions are the primary source of any information extracted in the course of a bookbuilding effort and take Inst_Alloc as a reflection of the banker's allocation strategy (see Cornelli and Goldreich, 1999, for evidence). Thus large price revisions, if they derive from such information, should be associated with large institutional allocations, other things equal. Moreover, there is likely to be a non-linearity in this relation: particularly valuable information requires particularly favorable allocations to induce investors to truthfully reveal their information. We therefore include both Revision and Revision+, the latter being equal to Revision whenever the offering is priced above the range, and zero otherwise. As argued earlier, price revisions should be viewed as being chosen simultaneously with allocations, so both Revision and Revision+ will be treated as endogenous. 
Large IPOs provide more currency for compensating informed investors and so may diminish the fraction of the offering they will expect. We control for this effect by including the variable Proceeds, defined as the natural log of gross proceeds raised in the offering (converted into U.S. dollars using exchange rates on the pricing day). This variable too is endogenous if issuers aim to minimize wealth losses associated with their offerings (Habib and Ljungqvist, 2001), and will therefore be treated as endogenous in the estimation.

We do not control separately for the regulatory constraints $B B \_$constraints and $B B \_$placings on allocations because our dependent variable Inst_Alloc measures institutional allocations relative to what is 'normal' in the local market, and so already takes into account the presence of constraints. ${ }^{9}$ We do, however, include a dummy variable indicating whether the offering was the result of a privatization of a state-owned firm. This reflects the fact that privatizations were quite commonly used as instruments of public policy aimed at broadening domestic share ownership or employee ownership (Jenkinson and Ljungqvist, 2001). Either would tend to favor retail investors. Thus the model specification for the banker's allocation policy is: ${ }^{10}$

$$
\text { Inst_Alloc }=f_{2}(\text { Revision, Revision }+, \text { Proceeds, Privatization })
$$

\subsection{Initial Returns}

In the Benveniste-Spindt framework, discounted share allocations constitute the compensation provided in exchange for investors' private information. Other things equal, large price revisions,

\footnotetext{
${ }^{9}$ Our results are not significantly changed when we include the two constraints dummies in the allocation equation $\left(\chi^{2}\right.$ test of equal coefficients across the two specifications: 8.56 with $p$-value 0.99 ).

${ }^{10}$ Allocations might also depend on initial returns: with greater allocations to institutions, underpricing need not be as high to compensate informed investors. However, while we find evidence that initial returns are significantly related to institutional allocations, we do not find that institutional allocations are significantly related to initial returns. This is consistent with underwriters setting allocation policy before setting pricing policy.
} 
reflecting a greater yield of private information, will carry the expectation of a larger discount. Again, there is likely to be a non-linearity in this relation: particularly valuable information requires some combination of favorable allocations and initial return to induce information revelation. We therefore include both Revision and Revision+ in the initial return model.

Holding the quantity of information revealed constant and assuming institutional investors are the source of this information, the percentage discount should be negatively related to the fraction of shares allocated to institutional investors. In other words, investors' incentive compatibility constraint for sharing their information demands a minimum dollar compensation that can be satisfied by infinitely many combinations of share price and quantity. Again, we do not control separately for the regulatory constraints $B B \_$constraints and $B B \_$placings. Rather, their effect on underpricing occurs indirectly through their effect on Revision and Inst_Alloc. Unreported tests indicate that the regulatory constraints do not have an independent, direct effect on underpricing.

Benveniste and Spindt argue that underwriters can reduce underpricing by 'bundling' deals. ${ }^{11}$ Essentially, a higher deal flow affords underwriters the opportunity to cut off informed investors from other, lucrative deals as punishment for misrepresenting their private information. Higher (expected) deal flow should therefore lead to a lower marginal cost of acquiring information. Similarly, and Benveniste, Busaba, and Wilhelm (2001) argue that during periods of high IPO volume, there is greater potential for issuers sharing the costs of information production, again leading to lower required underpricing returns.

We control for this effect with two variables. IPOVol, which captures aggregate deal flow, is defined as the number of local IPOs in the six weeks before to two weeks after the present IPO's pricing date. We include volume after the pricing date to allow for expectations regarding

\footnotetext{
${ }^{11}$ See Sherman (2000), especially proposition 2, for an elaboration of this point.
} 
bundling with deals that are already in the pipeline. Clearly the eight-week window is arbitrary; experimenting with different window sizes, we find that the results become progressively weaker the longer the window, but are not qualitatively altered with shorter windows. Our second variable is IBmktshare, which is defined as the lead manager's (or if more than one, the average of the lead managers') market share in the local market. IBmktshare may capture either bank-specific deal flow or the lead manager's reputation and thus certification ability. In either case, we expect it to be negatively related to initial returns. We treat IBmktshare as potentially endogenous, for it is possible that issuers choose their underwriters endogenously. Indeed, Habib and Ljungqvist (2001) show that treating underwriter choice as exogenous leads to the erroneous inference that more prestigious underwriters are associated with higher underpricing in the U.S. in the 1990s. Again, we use the full country samples to derive these variables.

Unlike in the U.S., where deals are typically priced only a few hours before trading begins, there is a substantial lag between pricing and trading in the three European countries (see Appendix D for details). During this post-pricing phase, further information could arrive from the secondary market, in the form of general market movements and spillovers from other IPOs that have begun trading in the meantime. We attempt to capture such information using MktRet ${ }_{\text {post- }}$ pricing, the market return between IPO $i$ 's pricing date and its fifth trading day (to coincide with our measurement of Initial Returns, see below), the post-pricing market volatility $\sigma_{-} M k t_{\text {post-pricing, }}$, and $m \_I R_{\text {post-pricing }}$, the average first-day return of all local offerings which open during this period.

Finally, we aim to control for firm-specific valuation uncertainty in three ways. Privatization IPOs generally involve more mature firms for which, presumably, more information is in the public domain, so their discounts may be smaller if discounts are at least in part compensation for private information. By the same reasoning, younger firms and firms in high-technology industries 
may be harder to value and thus carry higher initial returns. We therefore include a dummy for privatization IPOs, the natural log of one plus firm age at the time of the IPO, and a dummy which equals one for firms whose principal activities are in a high-tech industry. Since our sample cuts across countries, there is no consistent SIC code for assigning firms to the high-tech category. Instead, we base our assignments on a reading of the business description published in each firm's prospectus. On this basis, 232 of the 641 firms are classified as high-tech. These firms operate in the following range of industries: biotech, pharmaceuticals, medical instruments, software and hardware development, communications technology, advanced electronics, and specialty chemicals. In addition, we classify internet-related businesses as high-tech. ${ }^{12,13}$ This yields the following model for initial returns:

Initial Return $=f_{3}($ Revision, Revision+, Inst_Alloc, IPOVol, IBmktshare,

$$
\begin{aligned}
& \text { MktRet }{ }_{\text {post-pricing }}, \sigma \sigma_{-} k_{\text {post-pricing }}, m_{-} I R_{\text {post-pricing }} \\
& \text { Privatization, Age }, \text { Hightech) }
\end{aligned}
$$

where Initial Return is defined as the percentage return from the offer price to the closing price on the fifth trading day following listing. This is the same convention used by Ljungqvist et al. (2001) to obviate problems arising when daily price changes are subject to regulatory limits, as for instance in France. After-market prices were obtained from Datastream and Equityware for nonU.S. offerings and from CRSP for U.S. offerings.

\footnotetext{
${ }^{12}$ Another popular proxy for uncertainty is offer size. This is a curious proxy, for it is clearly endogenous to the offer price. Moreover, Habib and Ljungqvist (1998) prove that as a matter of identities, underpricing is strictly decreasing in offer size even when holding uncertainty constant. We thus refrain from using it.

${ }^{13}$ Hanley (1993) uses the width of the price range as a proxy for valuation uncertainty. In our data, this variable has no significant effect and we therefore exclude it from the model.
} 
As an alternative to Eq. (3), we estimate the impact of allocation policy on dollar underpricing, that is the total amount of money 'left on the table':

$$
\begin{gathered}
\text { Dollar Underpricing }=f_{3}(\text { Revision, Revision+, Inst_Alloc,IPOVol, IBmktshare, } \\
\qquad \begin{array}{c}
\text { MktRet } t_{\text {post-pricing }}, \sigma \_M k t_{\text {post-pricing }}, m_{-} I R_{\text {post-pricing }}, \\
\text { Privatization, Age, Hightech })
\end{array}
\end{gathered}
$$

where Dollar Underpricing equals Initial Return times the dollar gross proceeds. To a first approximation, maximizing the net proceeds of the offer (and thus the issuer's wealth) is equivalent to minimizing Dollar Underpricing. ${ }^{14}$ Following the argument in Habib and Ljungqvist (2001), the optimum is characterized by the issuer and its banker having chosen their allocation policy such that informed investors are just compensated for the value of disclosing their private information. A test for the optimality of allocation policies in our data can be based on the coefficient for Inst_Alloc in Eq. (3'), which captures the partial derivative of Dollar Underpricing with respect to institutional allocations. At the optimum, the partial derivative must be zero and so a zero coefficient for Inst_Alloc in Eq. (3') is consistent with issuers having chosen the allocation policy which minimizes Dollar Underpricing. ${ }^{15}$ A nonzero coefficient can be interpreted as follows. If informed investors expect too little compensation relative to the value of their private information, less information discovery will ensue in the pre-market, leading to a negative relation between Dollar Underpricing and Inst_Alloc: more money is left on the table, the less is allocated

\footnotetext{
${ }^{14}$ It is an approximation, for it ignores the dilution effect of selling new (primary) shares at a discount. For further details, see Habib and Ljungqvist (2001).

${ }^{15}$ Demsetz and Lehn (1985) first proposed this optimality test in the context of executive ownership. Note that it does not follow that the coefficient on Inst_Alloc in Eq. (3), which has percent underpricing on the left-hand side, should also be zero, if issuers are minimizing dollar rather than percent underpricing.
} 
to institutions. If, on the other hand, underwriters favor institutions with large allocations beyond the point where the issuer benefits from information production, perhaps in the expectation of kickbacks, Dollar Underpricing would increase in Inst_Alloc.

\subsection{Estimation}

The two models defined by the three structural Eqs (1)-(3) and (1)-(3') cannot be estimated using ordinary least squares, for each equation includes amongst its explanatory variables the dependent variable of one or both of the other equations. Specifically, the Initial Return is endogenous to IBmktshare and to both Revision and Inst_Alloc, which in turn are endogenous to each other and to Proceeds, which is endogenous to the offer price and thus related to both Initial Return and Revision. This has two consequences. First, it causes the endogenous variables to be correlated with the disturbances, leading to biased coefficients when estimated using OLS.

Second, since some of the explanatory variables are the dependent variables of other equations in the system, the error terms are expected to be correlated across equations, leading OLS standard errors to be biased upwards. Three-stage least squares (3SLS) provides consistent estimates of the coefficients and standard errors, as long as the model is identified, that is, if there is sufficient information to estimate the parameters of the structural model.${ }^{16}$ A necessary condition for identification is that the number of exogenous variables excluded from an equation is at least as large as the number of endogenous variables included in that equation. This 'order condition' is satisfied in our model.

\footnotetext{
${ }^{16}$ For further details, see Greene, 2000, pp. 692-693.
} 


\section{Results}

\subsection{Price discovery in primary markets}

Table 5 summarizes the 3SLS estimates of the model's structural parameters. The Revision equation yields several insights. Other things equal, constraints on allocation discretion result in smaller revisions relative to the indicative price range. Relative to unconstrained offerings, constraints on the split between retail and institutional investors reduce average revisions by 0.21 ( $p$-value $=3.8 \%$ ) while shutting out retail investors ex ante reduces average revisions by 0.29 $(p<1 \%)$. These are large effects, bearing in mind that the mean of Revisions is 0.65 . They are also similar in magnitude and, in fact, are not statistically different.

Institutional allocations (relative to expectation) have a positive and significant $(p=4.7 \%)$ effect on price revisions after allowing for the simultaneity between the two and controlling for regulatory constraints. This is consistent with the idea that, relative to retail investors, institutions are a valuable source of information. To illustrate the economic magnitude of the effect, consider a one standard deviation increase in institutional allocations from the mean. This will increase Revisions from 0.65 to 0.87 , holding all other covariates at their sample means. This effect is stronger than that measured by Hanley (1993) and Hanley and Wilhelm (1995). However, if we follow their lead by treating allocation policy as exogenous, the coefficient switches sign. This illustrates the extent of the simultaneity bias in treating allocations as exogenous.

The positive and significant coefficient $(p=2.4 \%)$ estimated for $m \_$Revision ${ }_{B B}$ is consistent with information revealed in contemporaneous offerings spilling over into the price discovery process. However, the economic magnitude of the effect is smaller than that of allocation policy: a one standard deviation increase in $m_{-}$Revision $_{B B}$ from the mean increases Revisions from 0.65 to only 0.71. At the same time, the negative coefficient estimated for $\sigma_{-} \operatorname{Revision}_{B B}(p<0.1 \%)$ is consistent 
with our prediction that the noisier is the information coming from other offerings, the less the offer price is increased relative to the indicative range. Underpricing of other deals during the bookbuilding phase, as measured by $m_{-} I R_{B B}$, also appears to spill over. The coefficient is positive and significant $(p<0.1 \%)$, but its economic magnitude is again relatively small. A two-quartile increase in contemporaneous underpricing, from the $1^{\text {st }}$ quartile of $3.9 \%$ to the $3^{\text {rd }}$ quartile of $24 \%$, increases average Revisions from 0.6 to 0.64 .

The coefficient estimated for $M_{k t R e t}$ is positive, as predicted, but not significant at conventional levels $(p=13.8 \%)$, while that for $\sigma_{-} M k t_{B B}$ is significantly negative $(p<0.1 \%)$. The former suggests that secondary market information, which is of course public, has only a weak influence when setting the offer price. The latter suggests that volatility in secondary markets like volatility in the primary market - affects price discovery negatively, and its economic effect is quite large: a one standard deviation increase in volatility reduces Revisions from 0.65 to 0.57 .

\subsection{Allocation policy}

The allocation equation yields one key insight: institutions are rewarded with above-normal allocations in return for revealing valuable information, the more so, the more positive the information. This is evidenced by the positive and significant coefficients for Revision $(p<1 \%)$ and Revision $+(p=1 \%)$. Other things equal, the expected cost of eliciting private information from investors is minimized when discounts are concentrated in states characterized by uniformly strong interest among investors which, presumably, are associated with the largest positive price revisions. This strategy minimizes leakage of surplus to investors providing weak indications of interest and therefore avoids undermining incentives for optimistic investors to be forthright with their opinions. To illustrate the economic magnitude of the effect, increasing Revision from the 
mean of 0.65 to 1 (corresponding to pricing at the top of the range) is associated with a $3.2 \%$ increase in institutional allocations, while increasing Revision further, by one standard deviation to 1.5 , is associated with a $35.6 \%$ increase in relative institutional allocations.

Consistent with our prediction that large IPOs provide more currency for compensating informed investors and so may diminish the fraction of the offering they will expect, we find that Proceeds is negatively and significantly related to institutional allocations $(p<1 \%)$. Of course, this coefficient also reflects placings in the U.K., which tend to be smaller and exclude retail investors, but the coefficient on Proceeds continues to be negative and significant if we control separately for placings.

Finally, we find no evidence of differences in allocations between privatizations and privatesector IPOs. Since privatizations tend to be large IPOs, it is conceivable that their effect on allocations is being subsumed in Proceeds. To check whether this is the case, we interacted Proceeds with the privatization dummy but found no differential effect of offer size on allocations between private-sector IPOs and privatizations.

\subsection{Initial Returns}

The underpricing equation provides strong evidence consistent with the notion of discounted share allocations being used strategically to encourage information production. First, we see strong confirmation of the partial adjustment phenomenon identified by Hanley (1993) in the positive and statistically significant coefficient estimated for Revision $(p<0.1 \%)$. Controlling for this effect, large institutional allocations are then associated with significantly smaller initial returns $(p=3.9 \%)$. Other things equal, it suggests that constraints on banker discretion, which translate into smaller institutional allocations, increase the indirect costs of going public. 
This result contrasts with Hanley and Wilhelm's (1995) finding that institutional allocations had little explanatory power for the cross-sectional variation in initial returns. It is quite sensitive to our treatment of allocation policy as an endogenous variable. If we follow Hanley and Wilhelm and treat institutional allocations as an exogenous explanatory variable in an OLS estimation of the underpricing equation, we find a positive and insignificant relation between underpricing and institutional allocations. We interpret this as evidence of bias associated with failure to treat allocation policy as endogenous.

Interestingly, the coefficient on Revision+ is not significant. This implies that particularly positive information does not result in greater underpricing and thus more money being left on the table overall. Instead, as we saw in the allocations equation, informed investors are rewarded for disclosing such information with particularly favorable allocations. This result contrasts with the findings of Benveniste, Ljungqvist, Wilhelm, and Yu (2001) for U.S. IPOs between 1985 and 2000. Since the primary difference in the structure of our empirical model is our capacity to control for allocation policy, it appears that the inability to do so may lead to mild distortion in the interpretation of the partial adjustment effect.

The coefficient estimated for IPOVol is negative as predicted but not significant, while the coefficient estimated for IBmktshare is negative and highly significant ( $p=1.3 \%)$. The former suggests that the indirect costs associated with underpricing are unaffected by the general level of primary market activity. The latter suggests that issuers who chose to employ underwriters with larger market shares experience lower underpricing. This result is consistent both with the notion of underwriter certification and with Benveniste, Busaba, and Wilhelm's (2001) prediction that certain banks have sufficient market power to spread the costs of information production more uniformly across deals. The effect of IBmktshare is large in economic magnitude: a one standard 
deviation increase in market share reduces underpricing from $22 \%$ to $9.2 \%$. Interestingly, IBmktshare is significant only if we treat it as endogenous: otherwise, its coefficient estimate decreases by $90 \%$, from -0.019 to -0.002 . This mirrors the finding of Habib and Ljungqvist (2001) that the effect of underwriter reputation on underpricing in the U.S. changes dramatically when issuers are assumed to choose their underwriters endogenously.

The post-pricing spillover variables have the expected signs and are mostly significant. In particular, higher initial returns elsewhere in the primary market tend to increase underpricing, which indicates the presence of 'hot issue' markets. Finally, other things equal, we find that companies in high-tech industries are more underpriced $(p=2.1 \%)$, consistent with differences in ex ante uncertainty. Firm age, while negatively related to underpricing as expected, is not significant, nor are privatizations associated with significantly different Initial Returns.

When Dollar Underpricing is introduced as the dependent variable, results are similar with the main exception that now the coefficient estimated for relative institutional allocations is not statistically significant. Recall that the sign of this coefficient can be interpreted as an indicator of the efficiency, to the issuer, of the pricing and allocation policy. A (statistically) zero coefficient is consistent with Habib and Ljungqvist's (2001) argument that issuing firms (and their banks on their behalf) optimize over a variety of deal characteristics to maximize net proceeds (or minimize wealth losses): on average, allocation policy appears to be chosen such that informed investors are just compensated for the value of disclosing their private information, rather than in the expectation of monetary kickbacks from favored investors. 


\section{Robustness}

In this Section we consider potential weaknesses in the analysis and outline a variety of experiments conducted to assess the robustness of our findings.

\subsection{Selectivity bias}

Our sample of IPOs is by no means comprehensive nor is it necessarily a random sample from the population. Thus, selectivity bias may exist. For instance, if the willingness of issuers or banks to share data with us is in some way systematically related to their bookbuilding behavior or some other characteristics, estimates based on such data may be misleading. To explore whether selectivity bias is a concern, we use a Heckman (1979) correction. ${ }^{17}$ The selection equation relates the probability of an observation being included in our final sample to log offer size and dummies for the country of listing and the IPO year, using a probit on the full country samples of Table 2, column [1]. This equation has very good fit, with a pseudo- $R^{2}$ of $47.4 \%$, and confirms that we are more likely to have complete information for larger offerings outside the U.S. and especially in France. Including the inverse Mills' ratio in the structural model, we find that its coefficient is very small in magnitude and insignificant in each of Eqs (1)-(3). A Wald test of the joint hypothesis that all three coefficients are zero cannot be rejected ( $p$-value $=0.57$ ). Moreover, only the Proceeds coefficient estimate changes by more than two standard errors following the Heckman correction (causing a sign change and point estimate of 0.009) while the privatization dummy becomes negative and significant in Eq. (2). However, since the inverse Mills' ratio is invariably insignificant, this is more likely a reflection of its collinearity with Proceeds than

\footnotetext{
${ }^{17}$ For details regarding selectivity corrections in structural estimation, see Maddala, 1983, pp. 234-235.
} 
evidence of selectivity bias. Thus, although the sample is not as comprehensive as we would like, we find no compelling evidence of selectivity bias.

\subsection{Normalization of institutional allocations}

The normalization of institutional allocations in the construction of Inst_Alloc is motivated by statistically significant differences in mean allocations across markets. ${ }^{18}$ But normalization also imposes a constraint on the estimation. Specifically, it is equivalent to the following:

1. instead of a single variable Inst_Alloc, use four interaction variables which equal nonnormalized institutional allocations times a dummy equaling 1 for country $i, i=1 \ldots 4$;

2. constrain the coefficients on the four interaction variables to equal $\beta$ / [in-country average institutional allocation for country $i]$;

3. estimate $\beta$.

Step 2 assumes that our normalization makes allocations comparable across countries so that there is a single $\beta$. We can test this by allowing the four interaction coefficients to vary by country. In the Revision equation we cannot reject the hypothesis that the four interaction coefficients are equal. On the other hand, there is evidence that the effect on underpricing varies across countries when allocations are modeled with a country-specific effect. The effect is significantly stronger in the U.K than in Germany, where in turn it is significantly stronger than in France.

\subsection{Endogeneity of the offering mechanism}

\footnotetext{
${ }^{18}$ The standard deviations of the mean allocations reported in Table 1, exclusive of U.K. placings, are not statistically different across markets with the marginal exception of the comparison between the U.S. and Germany. However, we have allowed for such differences in experiments with a normalization that measures the number of standard deviations from the in-market average institutional allocation. The results are available upon request but our conclusions are not sensitive to the alternative specification.
} 
Arguably, issuers have some ability to choose the mechanism through which they offer shares to the public, and so the constraints they are subject to. ${ }^{19}$ For instance, French and British firms could list in a less constrained country, assuming the additional cost of issuing abroad does not outweigh the benefit derived from escaping local constraints. We test this hypothesis using a variant of the Durbin-Wu-Hausman test of the null hypothesis that $B B_{-}$constraints is exogenous. The test is based on the difference in coefficients estimated under the null of exogeneity (Table 5) and the alternative of endogeneity. In our data, the test does not reject the null that $B B \_$constraints is exogenous $\left(\chi^{2}=0.06, p=81.1 \%\right)$. The same holds for BB_placings $\left(\chi^{2}=0.11, p=73.7 \%\right)$.

\subsection{U.K. Placings}

Pooling U.K. placings with other offering types yields benefits in estimation in terms of sample size. On the other hand, including U.K. placings may bias our estimation against finding significant effects, because there is little variation in their Inst_Alloc. For example, estimating the allocation equation only for U.K. placings, we would expect to obtain coefficient estimates close to zero because of the absence of allocation discretion. Estimation with the pooled sample might therefore lead to understatement of the effects of the explanatory variables.

To examine this possibility, we interact (1-BB_placings) with a variety of the right-hand-side variables in the structural model's three equations. The interaction coefficient estimates capture the effects of each variable on non-placings and therefore can be compared to the coefficients reported in Table 5. Wald tests indicate that the interaction coefficients are not statistically different from the coefficients reported in Table 5 either jointly $\left(\chi^{2}=0.99, p=98.6 \%\right)$ or individually ( $p$ values ranging from $39 \%$ to $97.7 \%$ ). Standard errors are somewhat larger, as we

\footnotetext{
${ }^{19}$ We are grateful to the referee and to Tim Jenkinson for alerting us to this possibility.
} 
would expect, but our central conclusions do not change..$^{20} \mathrm{We}$ interpret these findings as indicating that our results are not colored by the presence of U.K. placings.

\subsection{Non-linear allocation effects}

Allocations may have a non-linear effect on revisions and IPO initial returns. We investigate this possibility by defining a variable Inst_Alloc+ which equals (the instrumented) Inst_Alloc if Inst_Alloc $>\mathrm{X}$, and zero otherwise. Different values of X correspond to different notions of 'particularly large' institutional allocations. We find no evidence of non-linearities in the effect of allocations on revisions. There is, however, weak evidence that underpricing is further diminished in cases where institutions receive allocations that exceed in-market averages by more than $10 \%$, although all other relations are unaffected.

\subsection{Alternative specifications}

The structure of the model estimated in Table 5 depends heavily on (or alternatively, is constrained by) a broad interpretation of the Benveniste-Spindt theoretical framework. The signs of the coefficients for the conditioning variables are strongly consistent with the theory and jointly highly significant, indicating good fit. But of course, this does not rule out biases associated with omitted variables or other model misspecifications. Since many of the exogenous variables excluded from one or more of the structural equations have been included in extant, reduced-form analyses, we have experimented with various alternative specifications that involve including additional exogenous variables in each equation, subject to the identification constraints. Unless otherwise indicated, the central findings outlined in Section 5 are robust to these experiments.

\footnotetext{
${ }^{20}$ These results also are available upon request.
} 
In the revision equation, a noteworthy finding is a positive and statistically significant interaction between Inst_Alloc and the privatization dummy variable. In other words, a given increase in institutional allocations has a stronger effect on price revisions for privatizations. This finding is consistent with two non-mutually exclusive conjectures. First, privatizations often start from a lower base because allocation policies are explicitly designed to favor retail investors. Perhaps there are non-linear effects from allocation policy associated with rapidly diminishing marginal returns to the incentive effects of discretionary allocation. Moreover, because privatizations are typically large, a given increase in institutional allocations implies a larger dollar allocation to institutions than in the typical private-sector IPO. Perhaps this larger dollar allocation 'buys' more information production.

In the allocation equation, the primary finding from including additional exogenous variables is weak evidence that the spillover variables $m \_$Revision $_{B B}, M k t R e t_{B B}$, and $m_{-} I R_{B B}$ are negatively related to the fraction of the offering allocated to institutional investors. This could be interpreted as evidence that when more information spills over from the price revisions and underpricing of contemporaneous offerings as well as from broader market movements, there is less need to induce information production among institutional investors in the offering at hand.

The underpricing equation is the most widely explored in the existing literature. In light of Loughran and Ritter's (2001) finding of 'partial adjustment' to public information, including $M k t \operatorname{Ret}_{B B}$ and $\sigma_{-} M k t_{B B}$ in Eq. (3) seems a particularly useful exercise because it permits a test of whether recent market returns are fully incorporated in offer prices. In contrast to Loughran and Ritter, we find no evidence of partial adjustment to these measures of public information. Similarly, we find no evidence of direct effects associated with information spilling over from contemporaneous offerings. The stability of the remaining coefficient estimates suggests an 
absence of omitted variable bias in the original specification but the increase in standard errors suggests collinearity associated with the inclusion of the spillover variables. This is consistent with these variables being important determinants of Revision, which in turn is instrumented in part using these variables. We interpret this as evidence that the spillover variables have no direct effect on underpricing but have an indirect influence through their influence on price revisions reflected in the difference between indicative and offer prices.

Throughout the paper we have used a directional measure of price revisions. An alternative specification suggested by Hanley (1993) uses the absolute value of this directional measure. This specification enables estimation of the effect of explanatory variables on the magnitude but not the direction of information acquired during bookbuilding. Re-estimation of Eq. (1) using this specification yields little additional insight. This is a reflection of the fact that only 50 of the 641 sample offerings experience negative revisions, which in turn is a reflection of the fact that poorly received offerings are often withdrawn (see Benveniste, Ljungqvist, Wilhelm, and Yu, 2001, for related evidence from the U.S.).

Finally, Ljungqvist et al. (2001) find that pricing is influenced by both the presence of a U.S. bank as a senior member of the syndicate and the marketing of shares to U.S. investors. Accounting for this leaves all our results unchanged without generating significant insights. This is not surprising in view of the fact that France, Germany and the U.K. are among the most highly developed European markets where U.S. investors and U.S. banks have the least impact on the margin (Ljungqvist et al., 2001). 


\section{Conclusion}

If our empirical model, structured around the mechanism-design framework introduced by Benveniste and Spindt (1989), is an accurate representation of the incentive structure of primary equity markets, there appears to be evidence of a strategic link between allocations and measures of price discovery and cost. On net, discretion appears a good thing: it allows issuers to set more informed prices and thus minimize the wealth loss of going public.

Having said this, we recognize that discretion could be used to undermine the interests of issuing firms. For example, underpricing coupled with favoring institutional investors in the U.S. might reflect bankers serving their own interests and those of repeat investors. The alleged kickbacks discussed in the context of the SEC's current investigation represent an extreme manifestation of this conjecture. Loughran and Ritter (2001) suggest that issuing firms might willingly put up with this kind of behavior even if it has no apparent benefit for them. Although our findings are not consistent with this hypothesis, direct investigations of proprietary records, such as those currently underway in the U.S., might very well reveal evidence of unsavory behavior. But at a minimum, our results do provide tentative evidence that even if banks are selfserving in their exercise of discretion over the allocation of IPO shares, there appear to be benefits for issuing firms as well.

We qualify our conclusions because of the political nature of the question at hand and the fact that our sample period does not include the dot.com boom that appears the primary focus of regulatory investigations. But we also recognize that failure to reject the theoretical structure used in the analysis obviously does not imply that it accurately describes reality. On the other hand, the mechanism design framework provides an attractive null hypothesis if for no other reason than that it implies a good deal more structure than alternative theoretical perspectives. The framework 
is not a theory of underpricing. Rather it is a theory of the intermediary function given a particular incentive structure in the primary market and the early stages of the secondary market. In this sense, the theoretical framework subsumes Rock's (1986) winner's curse model (Benveniste and Wilhelm, 1990) and by way of the extension in Biais et al. (1999), subsumes the agency concerns raised by Baron (1982). In contrast to the estimation of reduced-form models more typical of the literature, we have tested a structural model built on this theory. We have not attempted to address the relative explanatory power of competing theories. However, the fact that our estimation of the structural model is so fully consistent with the theory leads us to believe that our conclusions are less likely spurious inferences regarding the linkage between allocation discretion and market efficiency. 


\section{Appendix A. Offer rules and mechanisms in Germany}

\section{Offer mechanisms}

Issuers can choose freely between fixed-price offerings, auctions, and bookbuilding.

\section{Allocation rules}

Fixed-price offerings can be allocated in a discretionary fashion. Unless chosen by the issuer, there are no pro rata requirements etc.

In auctions, orders are filled in descending order. The limit set for the last order met determines the single strike price of the auction.

Individual exchanges can, in principle, impose restrictions on IPO allocations as part of their listing requirements. The Neuer Markt in Frankfurt, by far the most important exchange for IPOs in Germany, requires issuers to adhere to the allocation guidelines of the Exchange Expert Commission at the Federal Ministry of Finance.

The guidelines were issued on June 7, 2000 (that is, after our sample period). They are largely aimed at increasing the transparency of the allocation process. For instance, they require that the percentage allocated to retail investors be published after the conclusion of the offer. Article 12 deals with allocations to retail investors in the case of oversubscription after a bookbuilding exercise. The article is aimed at ruling out 'subjective' criteria for determining allocations. It recommends issuers draw lots, allocate pro rata (within certain order sizes or across the offer as a whole), allocate according to time priority, or some other 'objective criteria'. The article applies only to 'fair' treatment within the retail allocation, not to allocations to institutions or the relative split between institutional and retail allocations.

Prior to the issuance of these guidelines, IPO allocations were absolutely at the issuer's/syndicate's discretion. 


\section{Appendix B. Offer rules and mechanisms in France}

Table B1: French methods of bringing securities to listing.

Method Description

Offre à prix minimal

(previously known as Mise en vente)
Invitation to the public to bid for securities of the issuer at or above a pre-specified minimum price. Bids must be limit orders; market orders are automatically deleted. Once bids are received, 'excessively high' bids are discarded. The Paris Bourse sets the single strike price at which orders are filled using the limit set on the last order met. If demand is excessive, the OPM can be repeated at a higher minimum price, or it can be converted into an offre à prix ferme (see below) at a (higher) fixed price.

Invitation to the public to subscribe for securities of the issuer at a fixed price (set in advance unless accompanied by a placement garanti, see below). Allocations are non-discretionary (pro-rated) except that issuers may invite subscriptions in Category A (usually up to 100 shares) and Category B (more than 100 shares) with preferential treatment (more favorable allocation/bid ratios) in Category A. In case of excessive demand (allocation/bid ratios below 0.8\%), the OPF may be repeated at a higher fixed price. If combined with a placement garanti, the price set in the OPF cannot exceed the price set in the placement.

Invitation to investors to participate in bookbuilding. Issuers may reserve the right to alter the price range. Allocations are at the bookrunner's discretion. In principle open to both retail and institutional investors.

Invitation to (usually) retail investors to submit price/quantity bids within the indicative price range (limits included). Issuers may reserve the right to alter the price range. Always accompanied by a placement garanti aimed at institutional investors. Allocations are nondiscretionary conditional on the price bid, though as in an OPF, issuers can invite bids in Category A and B with preference shown to smaller orders. Introduced July 24, 1998. 


\section{Appendix C. Offer rules and mechanisms in the United Kingdom}

Table C1: U.K. methods of bringing securities to listing (Yellow Book, chapter 4).

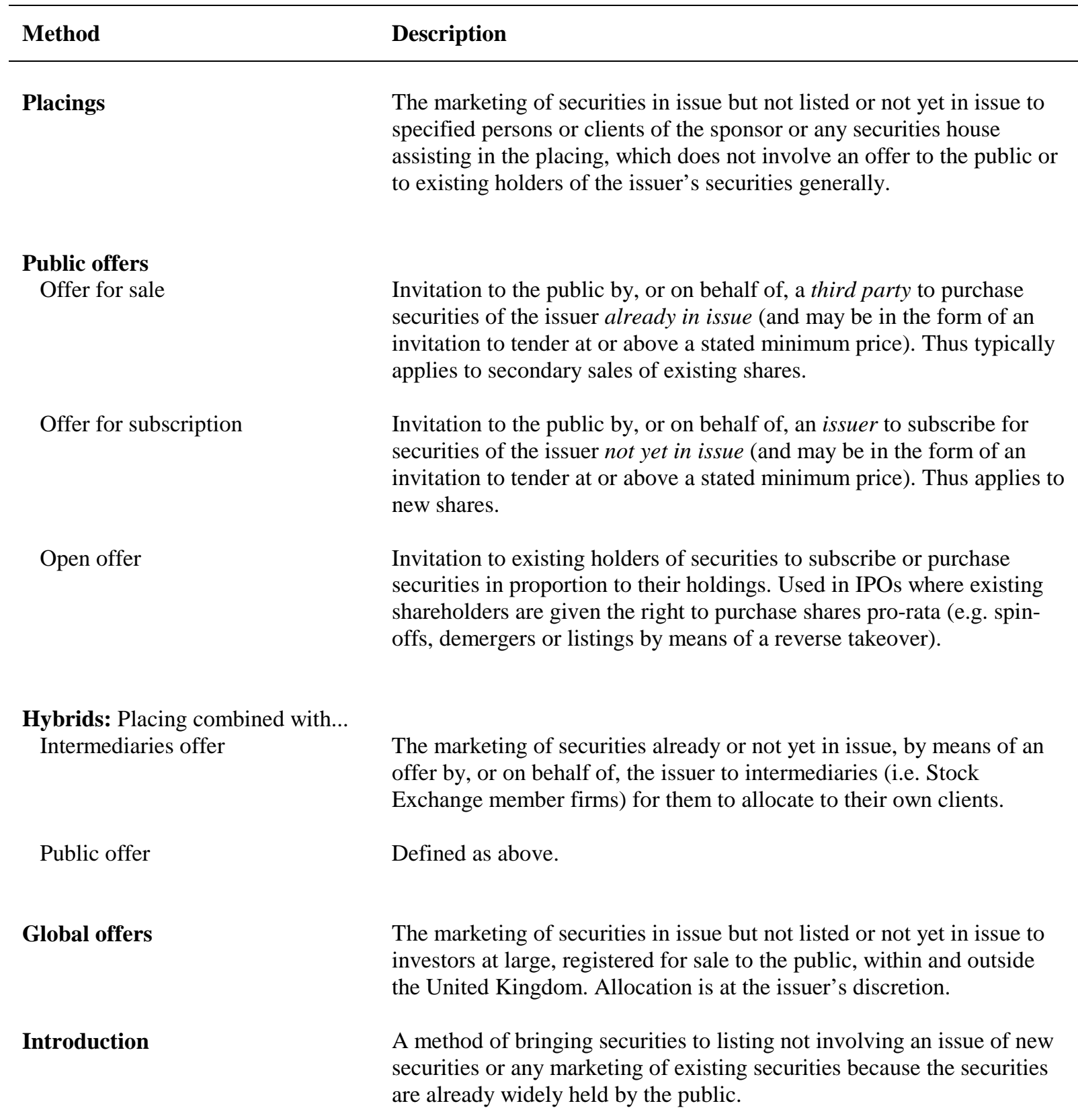

In addition, issuers can use "such other method as may be accepted by the London Stock Exchange (LSE) either generally or in a particular case".

The terminology 'public offer', as short-hand for a combined offer for sale and offer for subscription, is used where the offer includes both existing and new shares, though we shall use it 
as a collective noun for fixed-price offers. Public offers must be advertised in at least one national newspaper and are open to all.

In placings, shares are offered selectively, usually to City institutions. Private investors cannot normally apply. Shares may be set aside for employees.

\section{Rules regarding choice of offer method}

Until 1991, placings were allowed for offers raising up to $£ 15$ million, with public offers being mandatory for larger issues. Following the Initial Public Offers Review, chaired by Graham Ross Russell and which reported in July 1990, the LSE expanded the use of placings subject to making retail participation in IPOs mandatory for issues exceeding certain monetary thresholds. The new rules came into effect in January 1991. Companies offering between $£ 15$ million and $£ 30$ million were allowed to place their shares subject to the requirement that $75 \%$ or $£ 15$ million of the offer, whichever was the lesser, had to be offered to the public. The offer element could be satisfied via a traditional public offer or via the newly introduced 'intermediaries offer'. Issues raising more than $£ 30$ million should still come as public offers but the sponsor was free to place up to $50 \%$. Issues raising less than $£ 15$ million should be conducted as placings. On 1 December 1993, the thresholds were raised. Below $£ 25$ million: placing. Between $£ 25$ million and $£ 50$ million: mandatory public offer component. Above $£ 50$ million: mandatory public offer.

From January 1995, the LSE allowed scientific research based companies to choose freely between placings, public offers and hybrids without regard to offer size (Amendment 4). In January 1996, the LSE abolished restrictions on retail participation for all types of issuers. 


\section{Appendix D. Typical pricing sequences}

Calendar days relative to first trading day $(t=0)$, averages based on our samples.

France

(pure and hybrid bookbuilding)

$t$-20 preliminary prospectus, containing non-binding indicative price range, filed with and approved by the market regulator (COB - Commission des Opérations de Bourse)

pre-marketing to institutions

t-10 bookbuilding (placement garanti with or without offre à prix ouvert) opens: investors can submit their bids

$t-5 \quad$ the issue is priced; if hybrid offering, offre à prix ferme opens

$t=0 \quad$ trading begins

\section{Germany}

(bookbuilding)
$t-14 \quad$ preliminary prospectus released to public
pre-marketing to institutions
$t-10 \quad$ non-binding indicative price range set
$t-9$ price range published as amendment to preliminary prospectus
$t-8$ bookbuilding opens: institutions and retail investors can submit their bids
$t-3 \quad$ the issue is priced
$t=0 \quad$ trading begins

United Kingdom

(placing and hybrids)

t-27 'pathfinder prospectus' released to selected institutions. (This is similar to a 'red herring' in the U.S. though it does not (usually) contain a price range. Instead, the institutions are given a price indication that is not otherwise widely disseminated.)

pre-marketing to institutions

t-10 'impact day': the issue is priced and the final prospectus is made available to all interested investors. Investors can now apply for shares.

$t=0 \quad$ trading begins 


\section{References}

Aggarwal, R., 2000. Allocation of initial public offerings and flipping activity. Journal of Financial Economics, forthcoming.

Baron, D.P., 1982. A model of the demand for investment banking advising and distribution services for new issues. Journal of Finance 37, 955-976.

Benveniste, L.M., Spindt, P.A., 1989. How investment bankers determine the offer price and allocation of new issues. Journal of Financial Economics 24, 343-61.

Benveniste, L.M., Busaba, W., Wilhelm, W.J., 1996. Price stabilization as a bonding mechanism in new equity issues. Journal of Financial Economics 42, 223-255.

Benveniste, L.M., Busaba, W., Wilhelm, W.J., 2001. Information externalities and the role of underwriters in primary equity markets. Journal of Financial Intermediation, forthcoming.

Benveniste, L.M., Wilhelm, W.J., 1990. A comparative analysis of IPO proceeds under alternative regulatory environments. Journal of Financial Economics 28, 173-207.

Benveniste, L.M., Ljungqvist, A.P., Wilhelm, W.J., Yu, X., 2001. Evidence of information spillovers in the production of investment banking services. Unpublished working paper. New York University.

Biais, B., Bossaerts, P. Rochet, J.-C., 1999. An optimal IPO mechanism. Unpublished working paper. Université de Toulouse.

Biais, B., Faugeron-Crouzet, A.M., 2000. IPO auctions: English, Dutch, ... French and Internet. Journal of Financial Intermediation, forthcoming.

Cornelli, F., Goldreich, D., 1999. Bookbuilding and strategic allocation. Journal of Finance, forthcoming.

Cornelli, F., Goldreich, D., 2000. Bookbuilding: how informative is the order book? Unpublished working paper. London Business School.

Demsetz, H., Lehn, K., 1985. The structure of corporate ownership: causes and consequences. Journal of Political Economy 93, 1155-1177.

Greene, W.H., 2000. Econometric Analysis. $4^{\text {th }}$ ed. Prentice Hall.

Habib, M.A., Ljungqvist, A.P., 1998. Underpricing and IPO proceeds: a note. Economics Letters 61, 381-383.

Habib, M.A., Ljungqvist, A.P., 2001. Underpricing and entrepreneurial wealth losses: theory and evidence. Review of Financial Studies 14, 433-458.

Hanley, K., 1993. The underpricing of initial public offerings and the partial adjustment phenomenon. Journal of Financial Economics 34, 231-50. 
Hanley, K., Wilhelm, W.J., 1995. Evidence on the strategic allocation of initial public offerings. Journal of Financial Economics 37, 239-257.

Heckman, J., 1979. Sample selection bias as a specification error. Econometrica 47, 153-162.

Jenkinson, T.J., Ljungqvist, A.P., 2001. Going Public: The Theory and Evidence on How Companies Raise Equity Finance. $2^{\text {nd }}$ ed. Oxford University Press.

Ljungqvist, A.P., 1997. Pricing initial public offerings: further evidence from Germany. European Economic Review 41, 1309-1320.

Ljungqvist, A.P., Jenkinson, T.J., Wilhelm, W.J., 2001. Global integration in primary equity markets: the role of U.S. banks and U.S. investors. Review of Financial Studies, forthcoming.

Loughran, T., Ritter, J.R., 2001. Why don't issuers get upset about leaving money on the table in IPOs? Review of Financial Studies, forthcoming.

Lowry, M., Schwert, G.W., 2000. IPO market cycles: bubbles or sequential learning? NBER Working Paper No. 7935.

Maddala, G.S, 1983. Limited-dependent and Qualitative Variables in Econometrics. Cambridge University Press.

Rock, K. 1986. Why new issues are underpriced. Journal of Financial Economics 15, 187-212.

Sherman, A., 2000. IPOs and long-term relationships: an advantage of book building. Review of Financial Studies 13, 697-714.

Sherman, A., Titman, S., 2000. Building the IPO order book: underpricing and participation limits with costly information. Journal of Financial Economics, forthcoming. 
Table 1. Institutional IPO allocations by country of listing.

Rules on allocation discretion are formulated at the level of the country of listing, not the country of origin, so we report allocations by country of listing. Where a company lists in more than one country, we define its main listing as being in its home country, or if it only lists abroad as the country where the bulk of the offering is conducted. For instance, the Spanish company Terra Networks SA, which obtained listings on the stock exchanges of Madrid, Bilbao, Barcelona and Valencia as well as on Nasdaq, is classified as listing in Spain. Listings on EASDAQ are classified as Belgian (since Belgian law and regulations apply). Institutional and retail allocations sum to $100 \%$ of the shares sold. In most countries (including France, Germany, the U.K., and the U.S.), shares sold include overallotment shares where the overallotment option is exercised. Shares allocated to employees or to 'friends and family' are counted as retail allocations. We have no allocation data for IPOs in Ireland, the $15^{\text {th }}$ EU country. (But we do have allocation data for Irish companies going public abroad, in particular in the U.K.) Data for U.K. placings take into account shares set aside for employees, which are counted as retail allocations.

\begin{tabular}{lrrrcc}
\hline Country & $\mathrm{N}$ & Mean & St.dev. & Min & Max \\
\hline United Kingdom & 843 & 0.929 & 0.164 & 0.000 & 1.000 \\
$\quad$ Placings & 651 & 0.996 & 0.032 & 0.350 & 1.000 \\
$\quad$ Public offers & 6 & 0.000 & 0.000 & 0.000 & 0.000 \\
$\quad$ Hybrids and global & 186 & 0.725 & 0.181 & 0.136 & 1.000 \\
France & 244 & 0.761 & 0.182 & 0.000 & 1.000 \\
Germany & 144 & 0.577 & 0.209 & 0.000 & 1.000 \\
Italy & 52 & 0.637 & 0.154 & 0.000 & 0.972 \\
Sweden & 47 & 0.696 & 0.230 & 0.000 & 1.000 \\
Belgium & 45 & 0.650 & 0.215 & 0.210 & 1.000 \\
Finland & 40 & 0.764 & 0.159 & 0.300 & 0.300 \\
Netherlands & 29 & 0.680 & 0.201 & 0.000 & 0.927 \\
Spain & 27 & 0.739 & 0.232 & 0.250 & 0.974 \\
Portugal & 18 & 0.595 & 0.276 & 0.000 & 1.000 \\
Denmark & 10 & 0.672 & 0.246 & 0.300 & 0.972 \\
Greece & 3 & 0.131 & 0.146 & 0.045 & 1.000 \\
Austria & 1 & 0.725 & & & \\
Luxembourg & 1 & 0.974 & & & \\
EU15 & $\mathbf{1 5 0 4}$ & $\mathbf{0 . 8 2 3}$ & $\mathbf{0 . 2 2 3}$ & $\mathbf{0 . 0 0 0}$ & $\mathbf{1 . 0 0 0}$ \\
Hungary & 14 & 0.804 & 0.200 & 0.342 & 1.000 \\
Poland & 10 & 0.777 & 0.103 & 0.571 & 0.937 \\
Norway & 7 & 0.624 & 0.376 & 0.000 & 0.929 \\
Croatia & 1 & 0.629 & & & \\
Iceland & 1 & 0.000 & & & \\
Switzerland & 1 & 0.800 & & & \\
non-EU15 Europe & $\mathbf{3 4}$ & $\mathbf{0 . 7 3 0}$ & $\mathbf{0 . 2 5 8}$ & $\mathbf{0 . 0 0 0}$ & $\mathbf{1 . 0 0 0}$ \\
& & & & &
\end{tabular}


Table 1. Institutional IPO allocations by country of listing (cont'd).

\begin{tabular}{lrrrcc}
\hline Country & N & Mean & St.dev. & Min & Max \\
\hline Singapore & 60 & 0.590 & 0.246 & 0.000 & 0.925 \\
Hong Kong & 19 & 0.650 & 0.200 & 0.253 & 0.940 \\
South Africa & 9 & 0.423 & 0.335 & 0.000 & 0.899 \\
Turkey & 8 & 0.752 & 0.141 & 0.498 & 0.906 \\
Australia & 6 & 0.629 & 0.172 & 0.350 & 0.852 \\
Thailand & 4 & 0.676 & 0.049 & 0.602 & 0.700 \\
China & 3 & 0.933 & 0.115 & 0.800 & 1.000 \\
Malaysia & 2 & 0.837 & 0.231 & 0.674 & 1.000 \\
Bahrain & 1 & 0.528 & & & \\
Canada & 1 & 0.800 & & & \\
Indonesia & 1 & 0.804 & & & \\
Israel & 1 & 0.932 & & & \\
Japan & 1 & 0.500 & & & \\
Lebanon & 1 & 1.000 & & & \\
Philippines & 1 & 0.833 & & & \\
Venezuela & 1 & 0.822 & & & \\
Rest of World & $\mathbf{1 1 9}$ & $\mathbf{0 . 6 2 8}$ & $\mathbf{0 . 2 4 3}$ & $\mathbf{0 . 0 0 0}$ & $\mathbf{1 . 0 0 0}$ \\
United States & $\mathbf{3 2}$ & $\mathbf{0 . 6 6 3}$ & $\mathbf{0 . 1 5 5}$ & $\mathbf{0 . 0 0 0}$ & $\mathbf{1 . 0 0 0}$ \\
Total & $\mathbf{1 6 8 9}$ & $\mathbf{0 . 8 0 4}$ & $\mathbf{0 . 2 3 0}$ & $\mathbf{0 . 0 0 0}$ & $\mathbf{1 . 0 0 0}$ \\
Total w/o U.K. placings and public offers & $\mathbf{1 , 0 3 2}$ & $\mathbf{0 . 6 8 7}$ & $\mathbf{0 . 2 1 3}$ & $\mathbf{0 . 0 0 0}$ & $\mathbf{1 . 0 0 0}$ \\
\hline
\end{tabular}


Table 2. Sample characteristics.

\begin{tabular}{|c|c|c|c|c|c|}
\hline & $\begin{array}{c}\text { Whole sample } \\
{[1]}\end{array}$ & $\begin{array}{c}\text { w/ allocation } \\
\text { data } \\
{[2]} \\
\end{array}$ & $\begin{array}{c}\mathrm{w} / \text { allocation, } \\
\text { price range data } \\
{[3]}\end{array}$ & $\begin{array}{c}t \text {-test (z-test } \\
\text { for medians): } \\
{[1]=[2]}\end{array}$ & $\begin{array}{c}t \text {-test }(z \text {-test } \\
\text { for medians): } \\
{[2]=[3]}\end{array}$ \\
\hline \multicolumn{6}{|l|}{ France } \\
\hline Number of observations & 516 & 244 & 237 & & \\
\hline Pure bookbuilding & 43 & 26 & 26 & & \\
\hline Hybrid bookbuilding & 212 & 211 & 204 & & \\
\hline Fixed-price offering & 44 & 7 & 7 & & \\
\hline Auction & 185 & 0 & 0 & & \\
\hline Gross proceeds $(\$ \mathrm{~m})$ : mean & 74.125 & 143.805 & 146.500 & 1.741 & 0.046 \\
\hline Gross proceeds $(\$ \mathrm{~m})$ : median & 7.129 & 13.740 & 14.387 & $7.979^{* * * *}$ & 0.394 \\
\hline Underpricing (\%) & 16.5 & 17.1 & 17.4 & 0.205 & 0.089 \\
\hline Institutional allocations (\%) & n.a. & 76.1 & 76.0 & - & 0.057 \\
\hline Fraction privatizations (\%) & 3.1 & 4.9 & 4.6 & 1.181 & 0.142 \\
\hline \multicolumn{6}{|l|}{ Germany } \\
\hline Number of observations & 470 & 144 & 141 & & \\
\hline Bookbuilding & 377 & 141 & 141 & & \\
\hline Fixed-price offering & 92 & 2 & 0 & & \\
\hline Auction & 1 & 1 & 0 & & \\
\hline Gross proceeds $(\$ \mathrm{~m})$ : mean & 131.371 & 236.875 & 241.492 & 1.312 & - \\
\hline Gross proceeds $(\$ \mathrm{~m})$ : median & 39.738 & 35.648 & 37.526 & 0.136 & - \\
\hline Underpricing $(\%)$ & 40.2 & 49.0 & 49.4 & 1.264 & - \\
\hline Institutional allocations (\%) & n.a. & 57.7 & 58.4 & - & - \\
\hline Fraction privatizations $(\%)$ & 1.1 & 1.4 & 1.4 & 0.321 & - \\
\hline \multicolumn{6}{|l|}{ United Kingdom } \\
\hline Number of observations & 876 & 843 & 231 & & \\
\hline Placing & 651 & 651 & 126 & & \\
\hline Public offer & 12 & 6 & 0 & & \\
\hline Hybrid & 178 & 168 & 87 & & \\
\hline Global offer & 35 & 18 & 18 & & \\
\hline Gross proceeds $(\$ \mathrm{~m})$ : mean & 92.534 & 87.446 & 261.614 & 0.344 & $6.200^{* * *}$ \\
\hline Gross proceeds $(\$ \mathrm{~m})$ : median & 15.485 & 15.164 & 51.687 & 0.318 & $10.504^{* * *}$ \\
\hline Underpricing $(\%)$ & 39.6 & 32.0 & 11.9 & 0.915 & $2.398^{* *}$ \\
\hline Institutional allocations (\%) & n.a. & 93.0 & 86.3 & - & $5.286^{* * *}$ \\
\hline Fraction privatizations (\%) & 3.1 & 3.2 & 11.3 & 0.144 & $5.050^{* * *}$ \\
\hline \multicolumn{6}{|l|}{ United States } \\
\hline Number of observations & 2,353 & 32 & 32 & & \\
\hline Gross proceeds $(\$ \mathrm{~m})$ : mean & 110.400 & 315.984 & 315.984 & $3.523^{* * *}$ & - \\
\hline Gross proceeds $(\$ \mathrm{~m})$ : median & 50.000 & 172.250 & 172.250 & $5.541^{* * *}$ & - \\
\hline Underpricing $(\%)$ & 11.9 & 8.9 & 8.9 & $2.046^{* *}$ & - \\
\hline Institutional allocations (\%) & n.a. & 66.3 & 66.3 & - & - \\
\hline Fraction privatizations (\%) & n.a. & 0.0 & 0.0 & - & - \\
\hline \multicolumn{6}{|l|}{ All four } \\
\hline Number of observations & 6,403 & 1,263 & 641 & & \\
\hline Gross proceeds $(\$ \mathrm{~m})$ : mean & 75.387 & 121.744 & 215.292 & $4.214^{* * *}$ & $3.067^{* * *}$ \\
\hline Gross proceeds $(\$ \mathrm{~m})$ : median & 27.788 & 18.570 & 31.434 & $7.887^{* * *}$ & $8.721^{* * *}$ \\
\hline Underpricing (\%) & 25.8 & 30.6 & 22.0 & $1.661^{*}$ & $1.925^{*}$ \\
\hline Institutional allocations (\%) & n.a. & 85.4 & 75.4 & - & $9.833^{* * *}$ \\
\hline Fraction privatizations $(\%)$ & n.a. & 3.3 & 6.1 & - & $2.895^{* * *}$ \\
\hline
\end{tabular}

${ }^{* * * *},{ }^{* *},{ }^{*}=$ significant at $1 \%, 5 \%, 10 \%$ (two-tailed tests). 
Table 3. Definition of variables.

\begin{tabular}{|c|c|}
\hline Variable name & Definition \\
\hline \multicolumn{2}{|c|}{ Endogenous variables } \\
\hline Revision & $\begin{array}{l}\text { equals }\left(\text { Offer price }-P_{\text {low }}\right) /\left(P_{\text {high }}-P_{\text {low }}\right) \text {, where } P_{\text {high }} \text { and } P_{\text {low }} \text { are the high and } \\
\text { low end of the indicative price range, respectively }\end{array}$ \\
\hline Revision+ & $\begin{array}{l}\text { equals Revision if Revision }>1 \text { (offer price set above the indicative range), and } \\
0 \text { otherwise }\end{array}$ \\
\hline Inst_Alloc & $\begin{array}{l}\text { equals the fraction of shares allocated to institutions in IPO } i \text { divided by the } \\
\text { average fraction of shares allocated to institutions in all local offerings } i \neq j \text { in } \\
\text { the } 90 \text { calendar days preceding } i \text { 's first day of trading }\end{array}$ \\
\hline Initial Return & $\begin{array}{l}\text { equals } P_{5} / \text { Offer price }-1 \text {, where } P_{5} \text { is the firm's share price on its fifth day } \\
\text { of trading }\end{array}$ \\
\hline Proceeds & $\begin{array}{l}\text { equals the natural logarithm of dollar gross proceeds (in million), which is the } \\
\text { offer price times the number of shares sold (including overalloted shares) } \\
\text { converted into US dollars using exchange rates on the pricing day }\end{array}$ \\
\hline Dollar Underpricing & equals Initial Return times the dollar gross proceeds, in million \\
\hline IBmktshare & $\begin{array}{l}\text { equals the lead manager's (or if more than one, the average of the lead } \\
\text { managers') market share in the local market, in \%. Market share is the sum of } \\
\text { gross proceeds in all local offerings lead managed by bank } j \text { divided by total } \\
\text { proceeds raised in all offerings in that local market over the sample period } \\
\text { (offerings lead managed by more than one bank are allocated equally to the } \\
\text { lead managers). For offerings in the U.S., market shares are computed over } \\
\text { the five calendar years preceding firm } i \text { 's IPO. }\end{array}$ \\
\hline
\end{tabular}


Table 3. Definition of variables (cont'd).

\begin{tabular}{|c|c|}
\hline Variable name & Definition \\
\hline \multicolumn{2}{|c|}{ Exogenous variables } \\
\hline$m_{-}$Revision $_{B B}$ & $\begin{array}{l}\text { average Revision of all local offerings } i \neq j \text { between the setting of } i \text { 's price } \\
\text { range and its final pricing, weighted by the number of such offerings }\end{array}$ \\
\hline$\sigma_{-}$Revision $_{B B}$ & $\begin{array}{l}\text { standard deviation of Revision of all local offerings } i \neq j \text { between the setting } \\
\text { of } i \text { 's price range and its final pricing }\end{array}$ \\
\hline$M k t \operatorname{Ret}_{B B}$ & $\begin{array}{l}\text { return on the local market index between the setting of } i \text { 's price range and its } \\
\text { final pricing. Indices used: Germany - Datastream Germany index prior to } \\
\text { January } 1994 \text { and the DAX200 thereafter; France - Datastream France index } \\
\text { prior to January } 1991 \text { and the SBF } 250 \text { thereafter; U.K. - FT-SE All Share } \\
\text { index; U.S. - S\&P } 500 \text { index. }\end{array}$ \\
\hline$\sigma_{-} M k t_{B B}$ & $\begin{array}{l}\text { standard deviation of local daily market index returns between the setting of } \\
i \text { 's price range and its final pricing }\end{array}$ \\
\hline$m \_I R_{B B}$ & $\begin{array}{l}\text { average one-day Initial Return of all local offerings } i \neq j \text { between the setting } \\
\text { of } i \text { 's price range and its final pricing }\end{array}$ \\
\hline IPOVol & $\begin{array}{l}\text { the number of IPOs in the same local market as issue } i \text {, during the six weeks } \\
\text { before to two weeks after } i \text { 's pricing date }\end{array}$ \\
\hline MktRet $_{\text {post-pricing }}$ & $\begin{array}{l}\text { return on the local market index between } i \text { 's final pricing and the fifth day of } \\
\text { trading (to coincide with the period over which Initial Returns are computed) }\end{array}$ \\
\hline$\sigma \_M k t_{\text {post-pricing }}$ & $\begin{array}{l}\text { standard deviation of daily local market index returns between } i \text { 's final } \\
\text { pricing and the fifth day of trading }\end{array}$ \\
\hline$m_{-} I R_{\text {post-pricing }}$ & $\begin{array}{l}\text { average one-day Initial Return of all local offerings } i \neq j \text { between } i \text { 's final } \\
\text { pricing and its fifth day of trading }\end{array}$ \\
\hline BB_constraints & $\begin{array}{l}\text { dummy }=1 \text { for deals subject to constraints on allocation discretion, as defined } \\
\text { in Table } 4\end{array}$ \\
\hline BB_placings & dummy $=1$ for U.K. placings, as defined in Table 4 \\
\hline Privatization & dummy $=1$ if issue $i$ is a privatization \\
\hline Hightech & $\begin{array}{l}\text { dummy }=1 \text { if issue } i \text { operates in a 'high-tech' industry; see the text for industry } \\
\text { classifications }\end{array}$ \\
\hline Age & $\begin{array}{l}\text { equals one plus the natural logarithm of firm age, where firm age is the IPO } \\
\text { year minus the year of foundation as disclosed in IPO prospectuses }\end{array}$ \\
\hline
\end{tabular}


Table 4. Categorization of sample by restriction imposed on price discovery.

We categorize sample IPOs into three categories on the basis of the constraints imposed on price discovery. The 'unrestricted' category includes the 92 fixed-price offerings in Germany, on the grounds that underwriters retain allocation discretion in such deals (in contrast to, for instance, France and the U.K. where allocations in fixed-price deals are pro rata or balloted). The $B B_{-}$constraints category includes the 185 fixed-price and 44 auction offerings in France, as well as one auction in Germany.

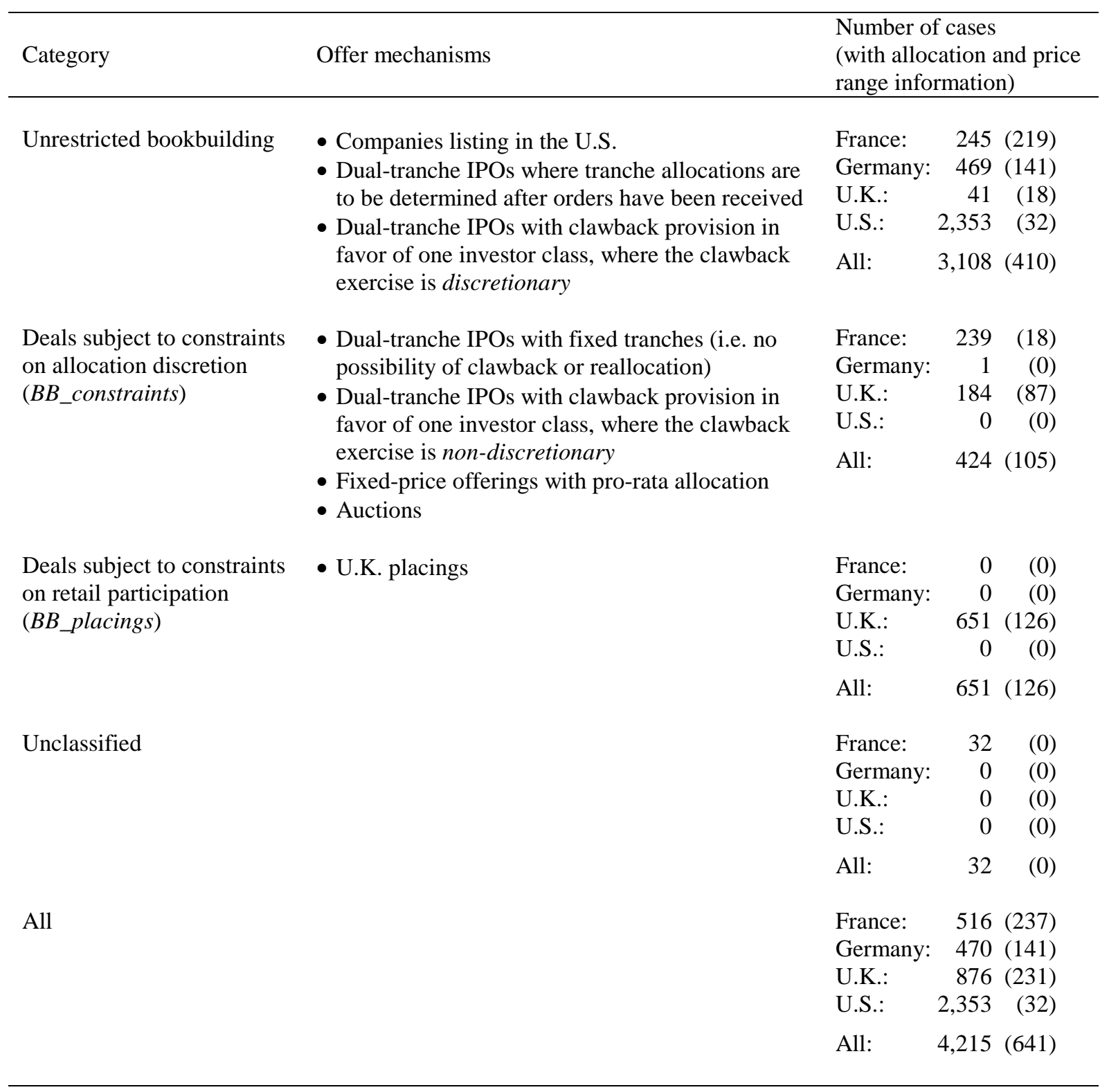


Table 5. Regression results.

The two systems described by Eqs (1)-(3) and (1)-(3') are estimated separately using three-stage least squares. Year dummies were included in the first-stage regressions. All variables are defined in Table 3. Revision, Revisiont, Inst_Alloc, Initial Return, Proceeds, Dollar Underpricing, and IBmktshare are treated as endogenous. All other regressors are treated as exogenous. Standard errors are given in italics below the coefficient estimates. Number of observations: 641 (237 in France, 141 in Germany, 231 in the U.K., and 32 in the U.S.). ${ }^{* * *},{ }^{* *},{ }^{*}=$ significant at 1\%, $5 \%, 10 \%$ (two-tailed $\mathrm{Z}$ test).

\begin{tabular}{|c|c|c|c|c|c|c|}
\hline $\begin{array}{r}\text { Eq. } \\
\text { Dependent var. }\end{array}$ & Revision & $\begin{array}{c}\text { (2) } \\
\text { Inst_Alloc }\end{array}$ & $\frac{\text { (3) }}{\text { Initial Return }}$ & $\begin{array}{c}\text { (1) } \\
\text { Revision }\end{array}$ & $\frac{(2)}{\text { Inst_Alloc }}$ & $\begin{array}{c}\left(3^{\prime}\right) \\
\text { Dollar } \\
\text { Underpricing }\end{array}$ \\
\hline Inst_Alloc & $\begin{array}{l}0.682^{* *} \\
0.343\end{array}$ & & $\begin{array}{c}-0.420^{* * *} \\
0.203\end{array}$ & $\begin{array}{l}0.858^{* *} \\
0.360\end{array}$ & & $\begin{array}{r}-135.189 \\
119.016\end{array}$ \\
\hline Revision & & $\begin{array}{l}0.163^{* * *} \\
0.056\end{array}$ & $\begin{array}{l}0.527^{* * * *} \\
0.083\end{array}$ & & $\begin{array}{l}0.176^{\text {**** }} \\
0.056\end{array}$ & $\begin{array}{l}85.611^{*} \\
48.161\end{array}$ \\
\hline Revision+ & & $\begin{array}{l}0.216^{* *} \\
0.084\end{array}$ & $\begin{array}{l}0.030 \\
0.113\end{array}$ & & $\begin{array}{l}0.214^{\text {** }} \\
0.085\end{array}$ & $\begin{array}{l}-2.756 \\
64.939\end{array}$ \\
\hline Proceeds & & $\begin{array}{c}-0.078^{* * * *} \\
0.023\end{array}$ & & & $\begin{array}{l}-0.071^{* * *} \\
0.023\end{array}$ & \\
\hline$m_{-}$Revision $_{B B}$ & $\begin{array}{l}0.004^{* *} \\
0.002\end{array}$ & & & $\begin{array}{l}0.004^{* *} \\
0.002\end{array}$ & & \\
\hline$\sigma_{-}$Revision $_{B B}$ & $\begin{array}{l}-0.191^{* * *} \\
0.046\end{array}$ & & & $\begin{array}{c}-0.215^{* * *} \\
0.049\end{array}$ & & \\
\hline$m \_I R_{B B}$ & $\begin{array}{l}0.214^{* * * *} \\
0.046\end{array}$ & & & $\begin{array}{l}0.140^{* * * *} \\
0.049\end{array}$ & & \\
\hline $\operatorname{MktRet}_{B B}$ & $\begin{array}{l}0.890 \\
0.600\end{array}$ & & & $\begin{array}{l}0.907 \\
0.660\end{array}$ & & \\
\hline$\sigma_{-} M k t_{B B}$ & $\begin{array}{c}-15.661^{* * *} \\
4.483\end{array}$ & & & $\begin{array}{c}-13.911^{* * * *} \\
4.872\end{array}$ & & \\
\hline BB_constraints & $\begin{array}{c}-0.211^{* *} \\
0.101\end{array}$ & & & $\begin{array}{r}-0.149 \\
0.109\end{array}$ & & \\
\hline BB_placings & $\begin{array}{c}-0.286^{* * * *} \\
0.066\end{array}$ & & & $\begin{array}{c}-0.257^{* * *} \\
0.069\end{array}$ & & \\
\hline IPOVol & & & $\begin{array}{c}-0.0002 \\
0.001\end{array}$ & & & $\begin{array}{l}0.550 \\
0.849\end{array}$ \\
\hline IBmktshare & & & $\begin{array}{c}-0.019^{* *} \\
0.007\end{array}$ & & & $\begin{array}{r}-1.592 \\
4.613\end{array}$ \\
\hline MktRet $t_{\text {post-pricing }}$ & & & $\begin{array}{l}0.785 \\
0.592\end{array}$ & & & $\begin{array}{r}-116.136 \\
380.462\end{array}$ \\
\hline$\sigma_{-} M k t_{\text {post-pricing }}$ & & & $\begin{array}{c}-11.164^{* * *} \\
3.488\end{array}$ & & & $\begin{array}{c}-2809.968 \\
2208.104\end{array}$ \\
\hline$m_{-} I R_{\text {post-pricing }}$ & & & $\begin{array}{l}0.095^{\text {*** }} \\
0.035\end{array}$ & & & $\begin{array}{l}34.937 \\
22.780\end{array}$ \\
\hline Privatization & & $\begin{array}{l}0.076 \\
0.095\end{array}$ & $\begin{array}{l}0.041 \\
0.104\end{array}$ & & $\begin{array}{l}0.056 \\
0.096\end{array}$ & $\begin{array}{c}195.706^{* * *} \\
65.094\end{array}$ \\
\hline Hightech & & & $\begin{array}{l}0.082^{* *} \\
0.036\end{array}$ & & & $\begin{array}{l}42.356^{*} \\
22.944\end{array}$ \\
\hline Age & & & $\begin{array}{r}-0.019 \\
0.015\end{array}$ & & & $\begin{array}{r}-9.390 \\
9.535\end{array}$ \\
\hline Constant & $\begin{array}{l}0.143 \\
0.364\end{array}$ & $\begin{array}{l}1.154^{* * * *} \\
0.090\end{array}$ & $\begin{array}{l}0.446^{* *} \\
0.203\end{array}$ & $\begin{array}{r}-0.035 \\
0.382\end{array}$ & $\begin{array}{l}1.122^{* * *} \\
0.091\end{array}$ & $\begin{array}{l}121.932 \\
120.300\end{array}$ \\
\hline all coeff $=0 ?\left(\chi^{2}\right)$ & $101.8^{* * *}$ & $35.3^{* * *}$ & $114.0^{* * * *}$ & $85.9^{* * *}$ & $34.8^{* * * *}$ & $40.6^{* * *}$ \\
\hline
\end{tabular}

